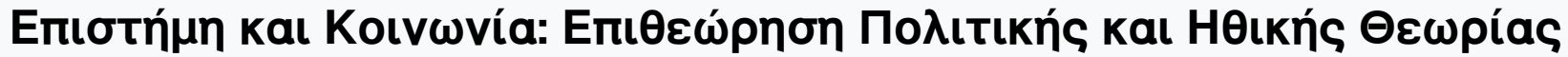

Tóp. 27 (2011)

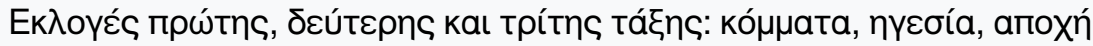

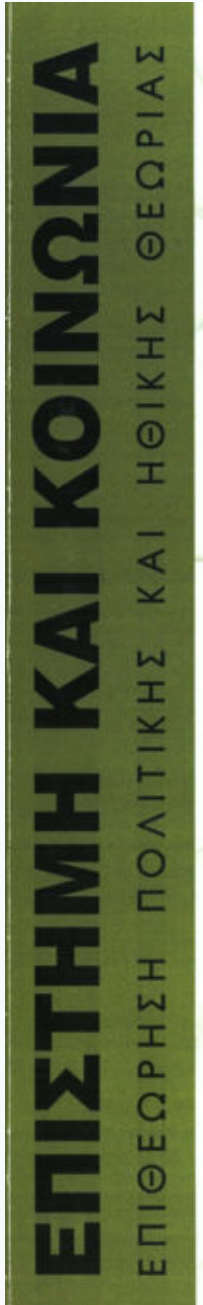

\author{
Tєu்xos 27 \\ Ka入окаiрı 2011 \\ http://www.media.uoa.gr/sas

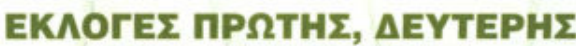

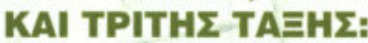

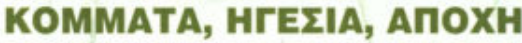

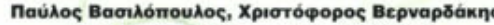

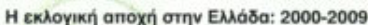

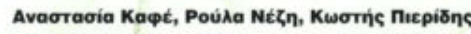

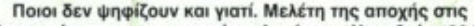

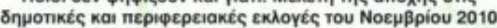

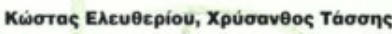

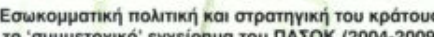

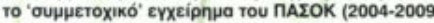

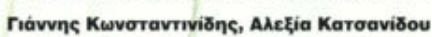

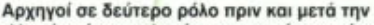

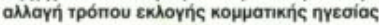

$$
\text { Iraúpos Ikpivns }
$$

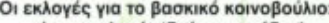

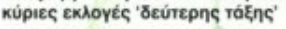 \\ réwpyıos Bגáxos

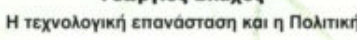 \\ Aıpıdia BouAßoúdn

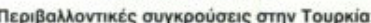

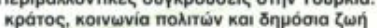 \\ Bàıa Apavitou

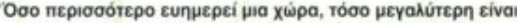

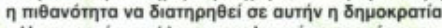

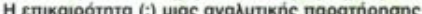 \\ Baơ৯ıkn rewpyiáðou

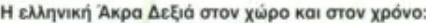

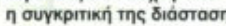

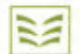

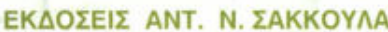

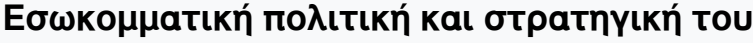

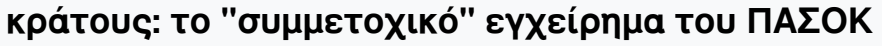
(2004-2009)

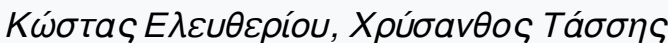

doi: $10.12681 /$ sas.805

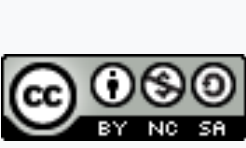

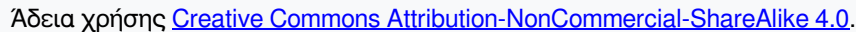

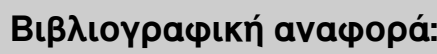

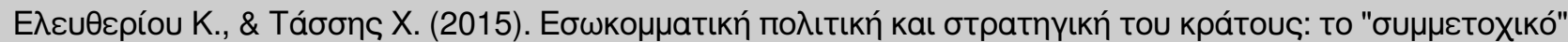

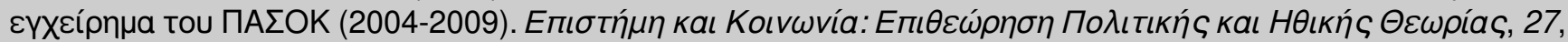
55-81. https://doi.org/10.12681/sas.805 


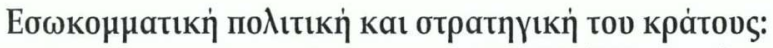

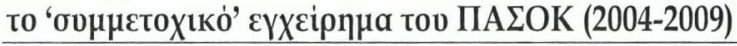

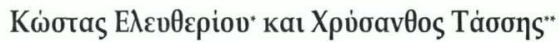

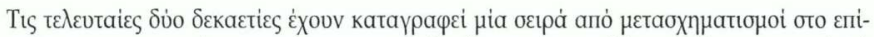

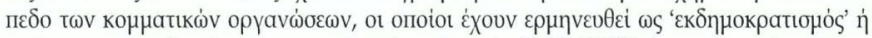

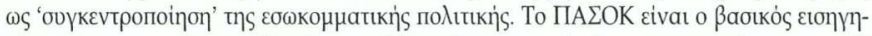
тท่

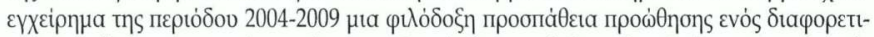

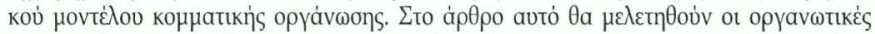

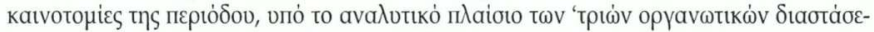

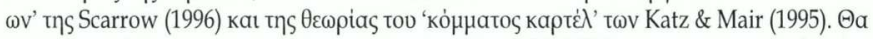

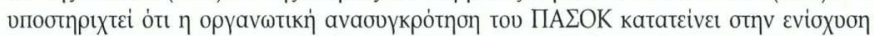

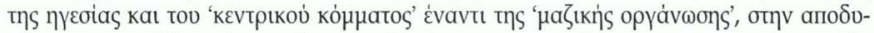

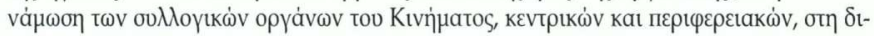

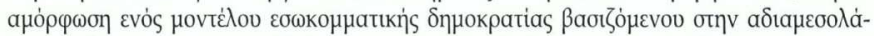

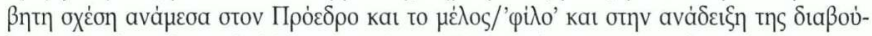

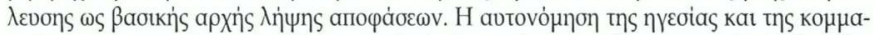

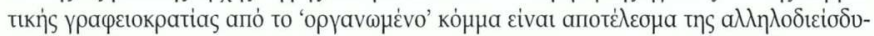

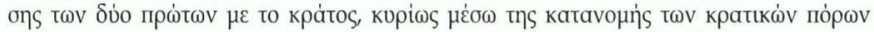

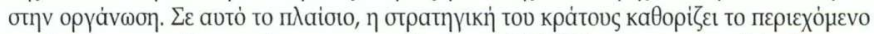

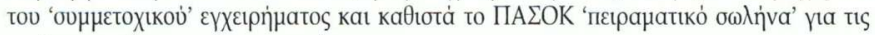

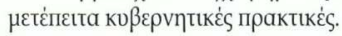

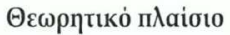

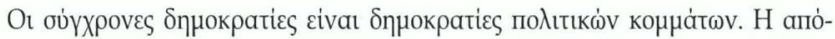

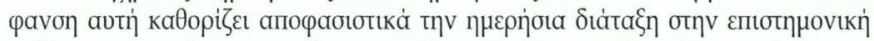

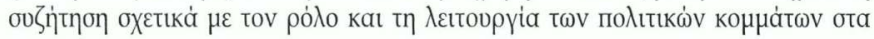

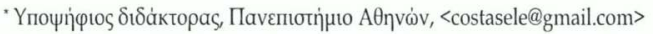

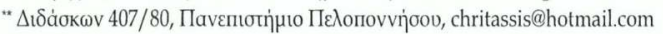

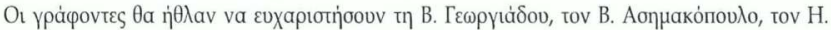

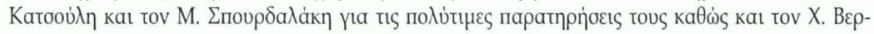

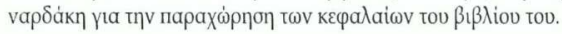




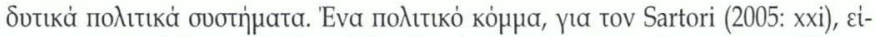

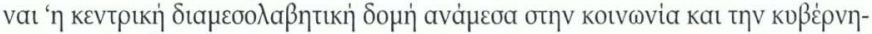

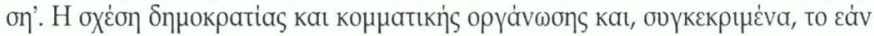

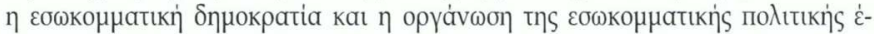

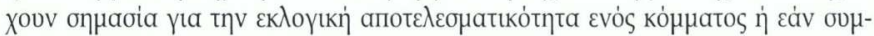

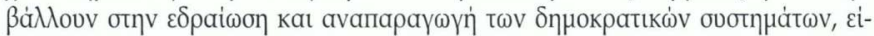

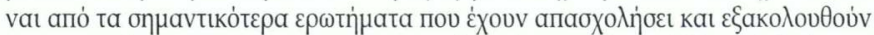

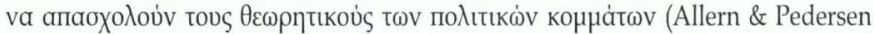

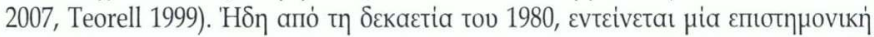

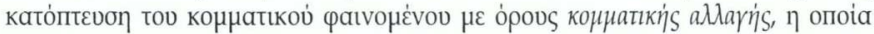

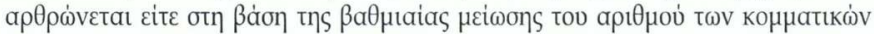
$\mu \varepsilon \lambda \omega \dot{~(K a t z, ~ M a i r ~ e t ~ a l . ~ 1992, ~ M a i r ~ \& ~ v a n ~ B i e z e n ~ 2001, ~ S c a r r o w ~ \& ~ G e z g o r ~ 2010) ~ \varepsilon i-~}$

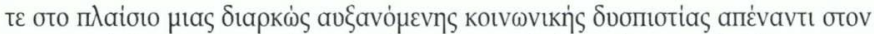

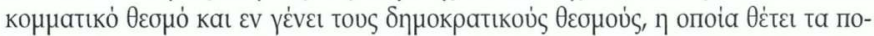

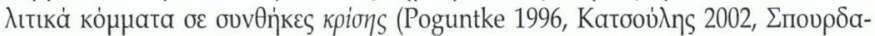

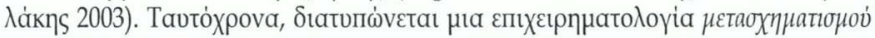

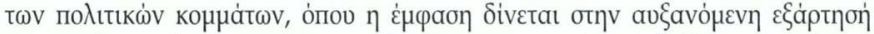

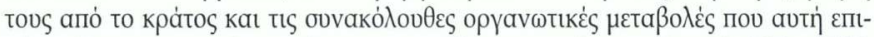

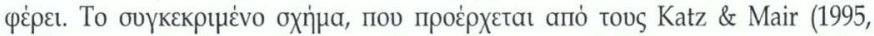

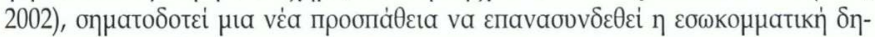

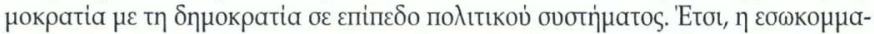

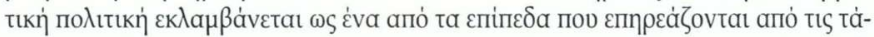

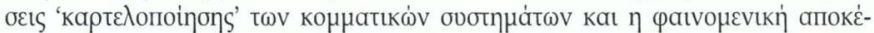

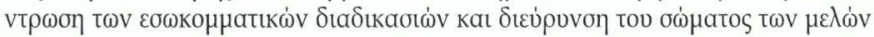

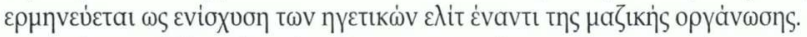

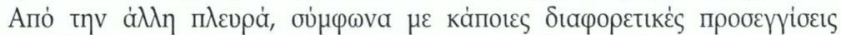

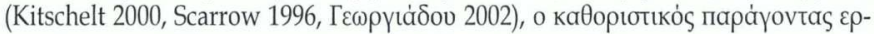

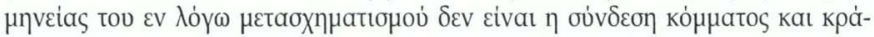

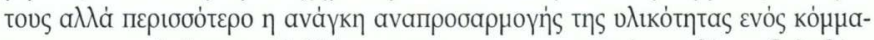

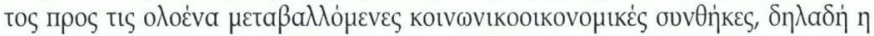

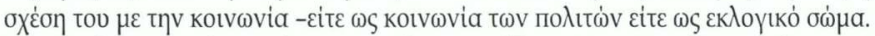

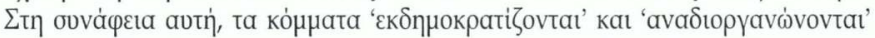

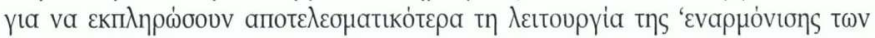

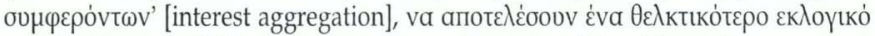

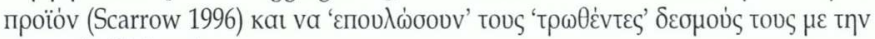

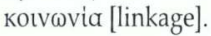

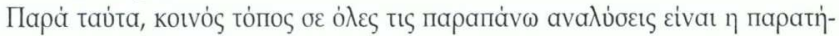

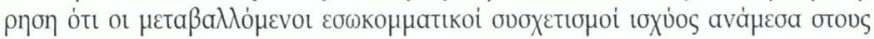




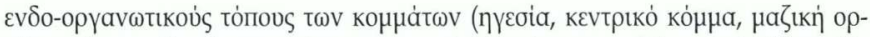

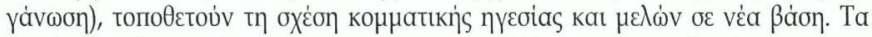

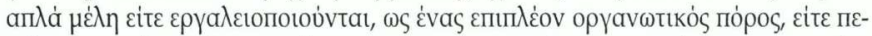

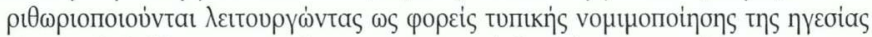

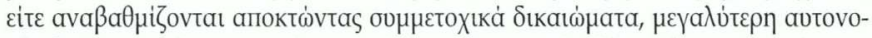

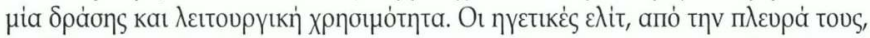

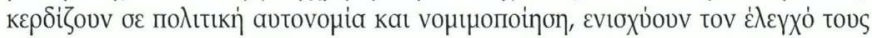

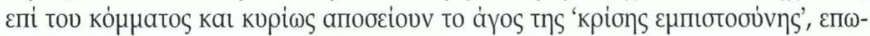

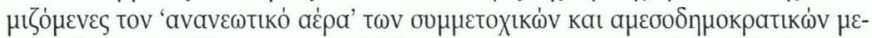

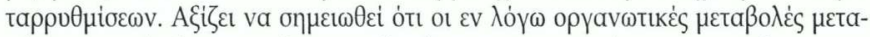

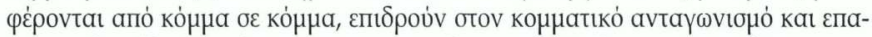

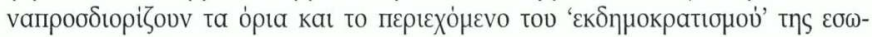

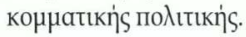

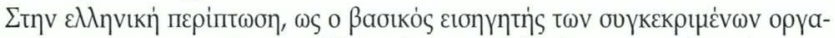

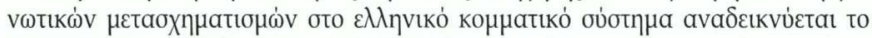

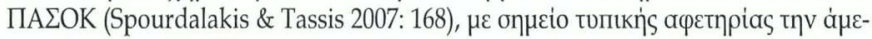

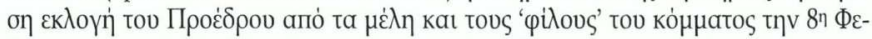

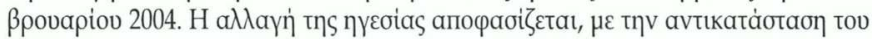

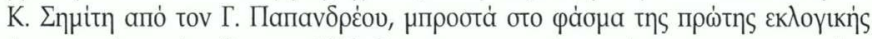

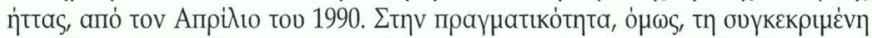

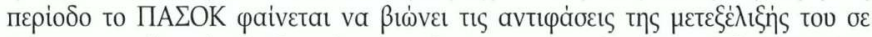

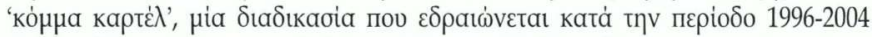

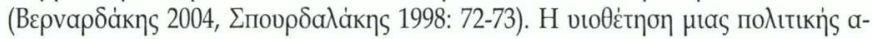

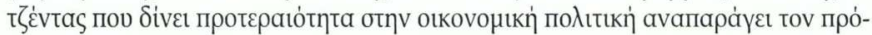

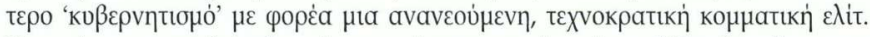

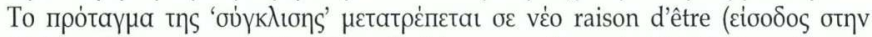

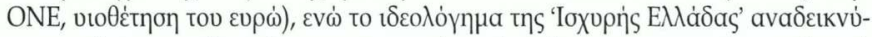

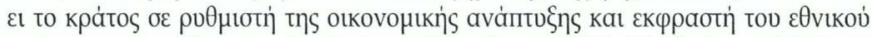

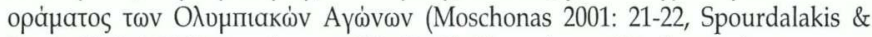

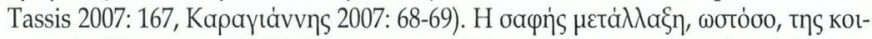

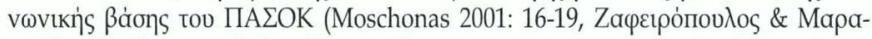

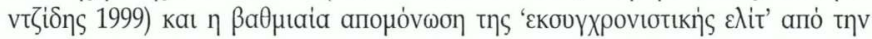

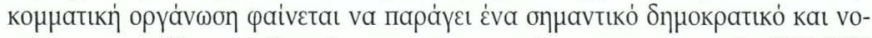

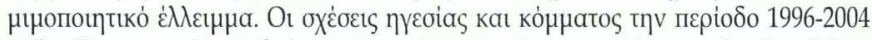

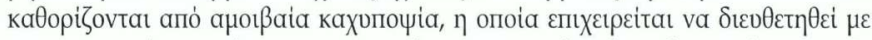

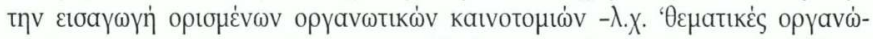

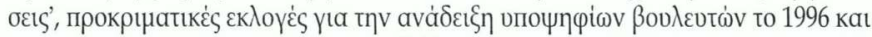

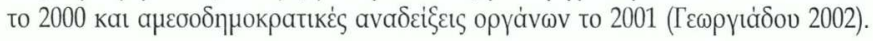




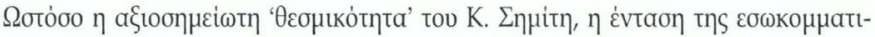

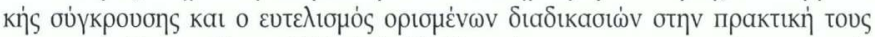

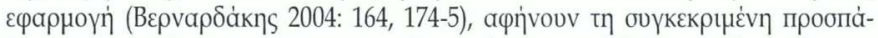

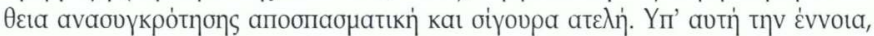
то $\varepsilon \gamma \chi \varepsilon i \rho \eta \mu \alpha$ тп

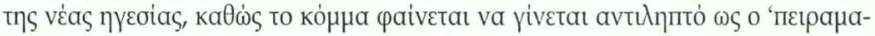

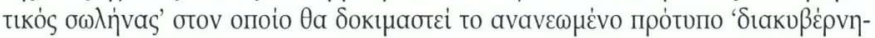

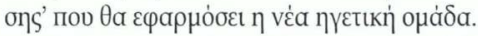

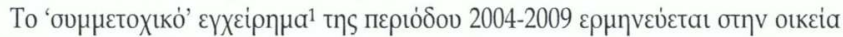

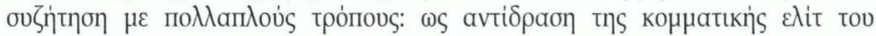

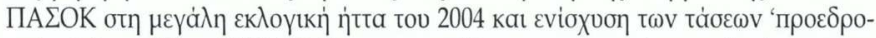

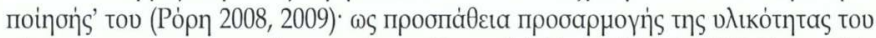

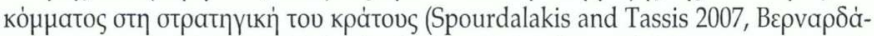

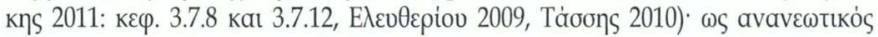

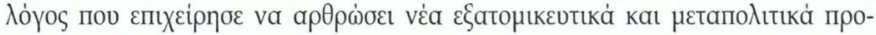

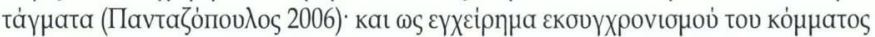

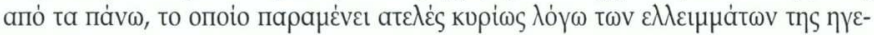

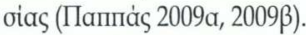

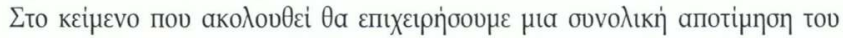

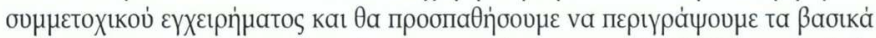

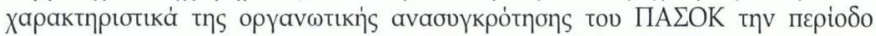

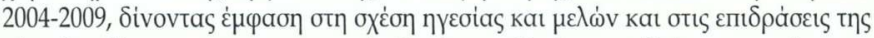

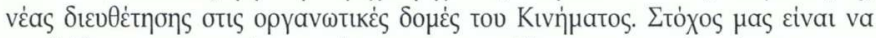

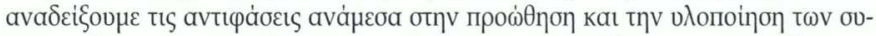

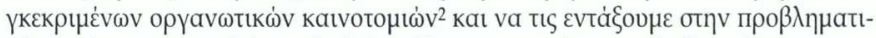

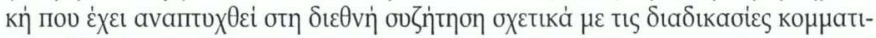

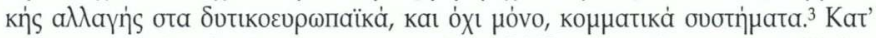

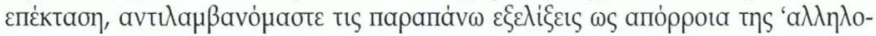

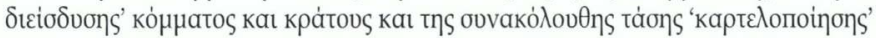

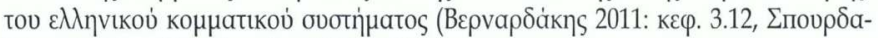

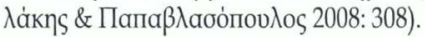

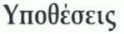

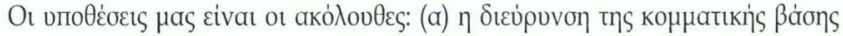

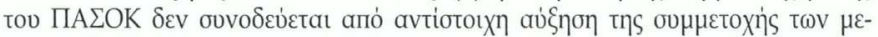

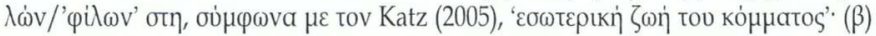

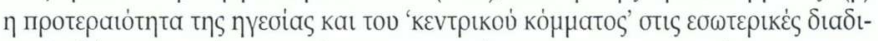

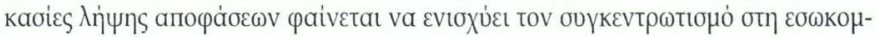




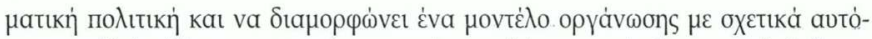

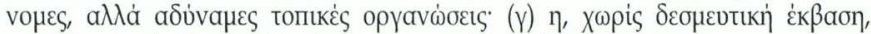

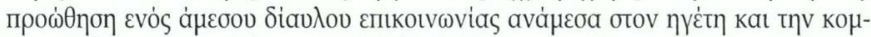

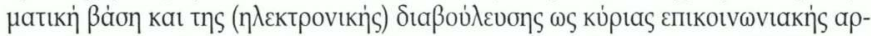

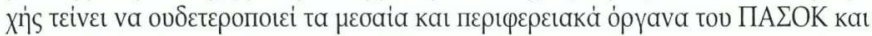

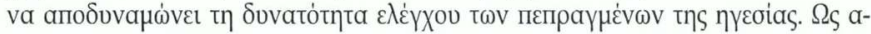

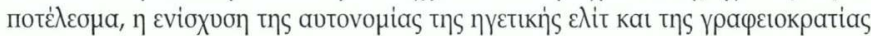

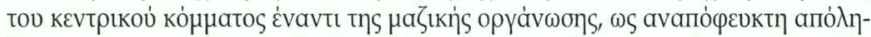

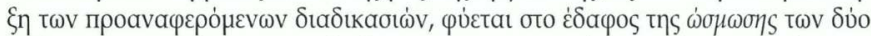

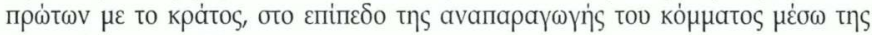

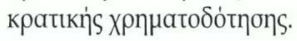

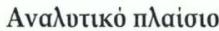

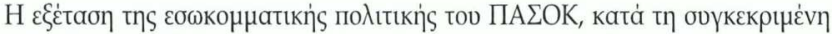

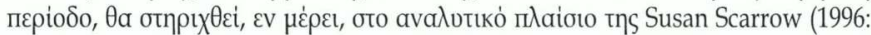

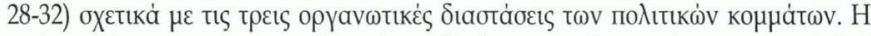

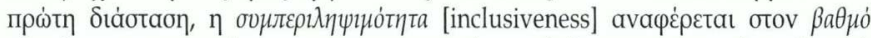

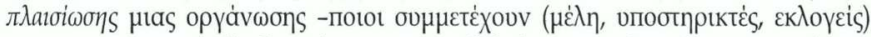

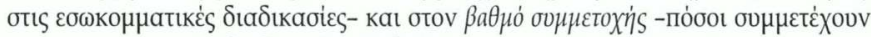

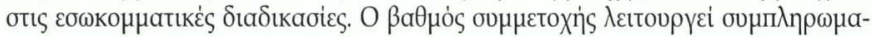

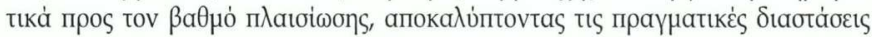

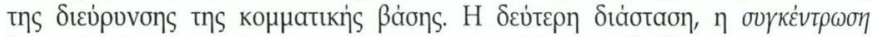

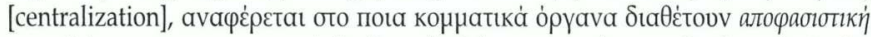

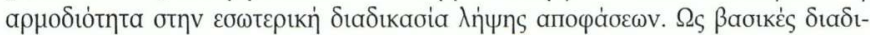

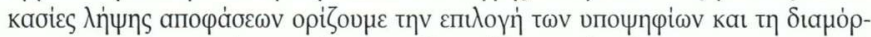

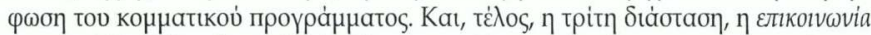

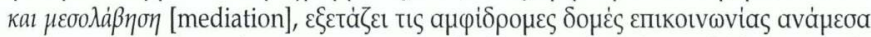

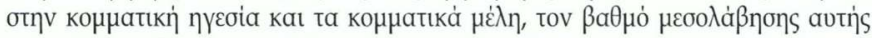

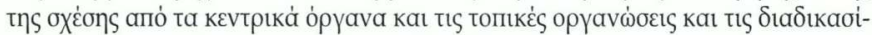

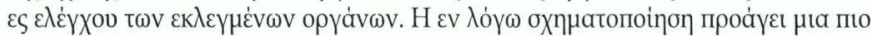

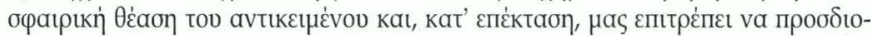

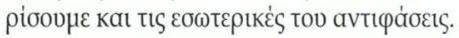

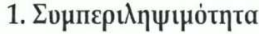

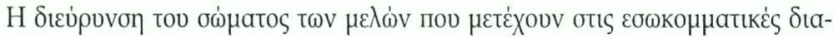

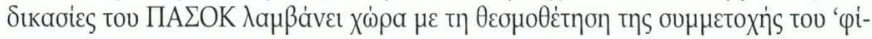

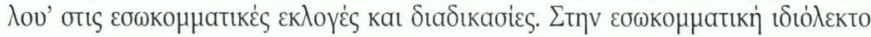




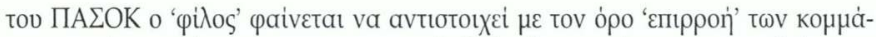

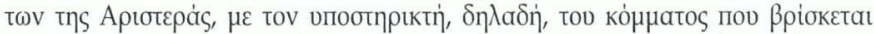

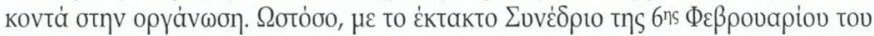

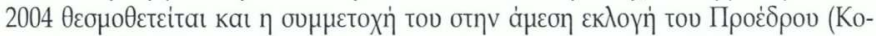

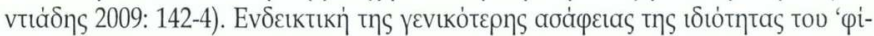

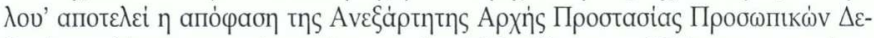

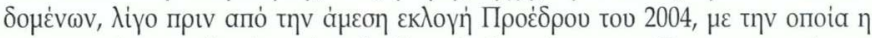

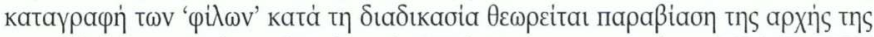

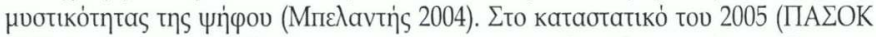

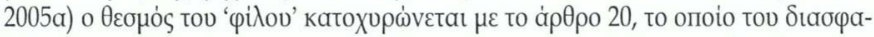

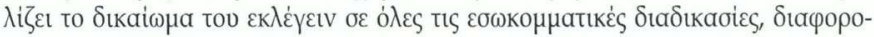

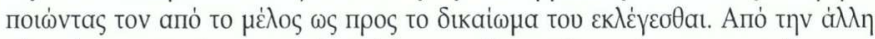

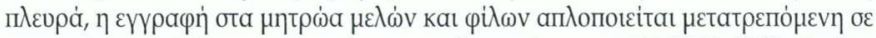

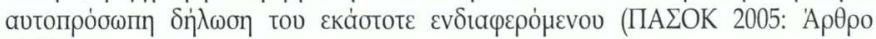
$18 / 3)$.

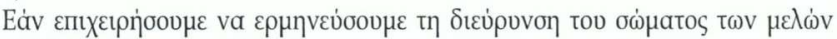

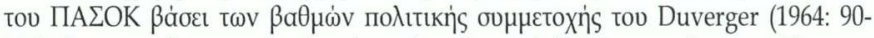

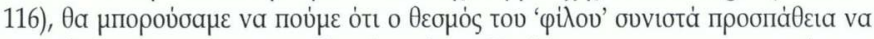

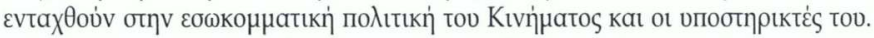

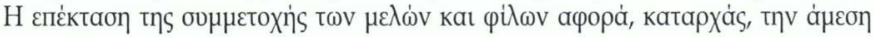

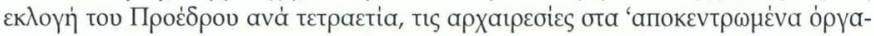

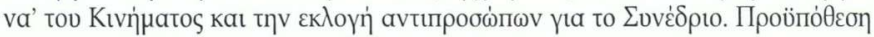

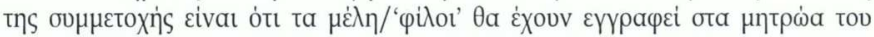

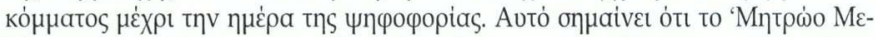

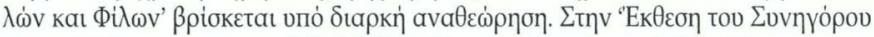

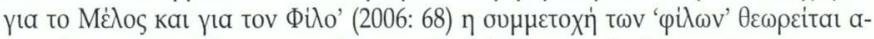

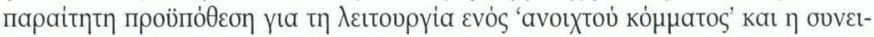

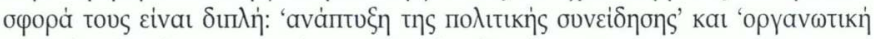

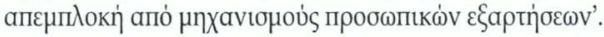

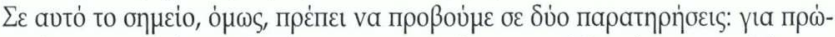

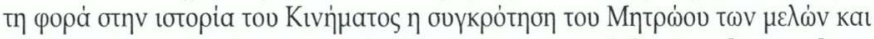

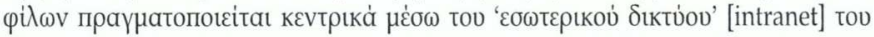

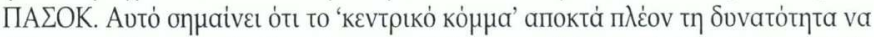

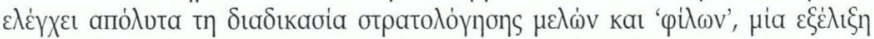

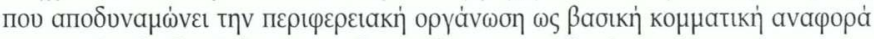

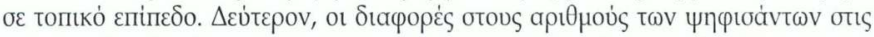

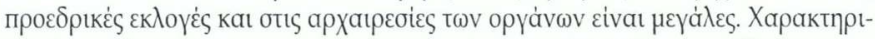

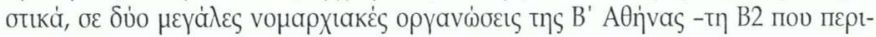




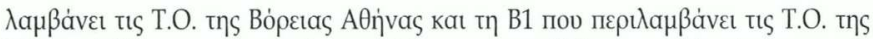

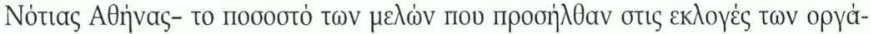

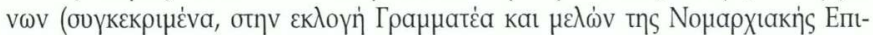

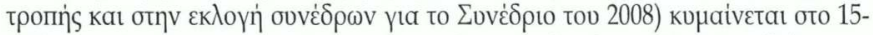

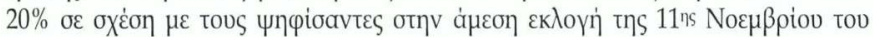

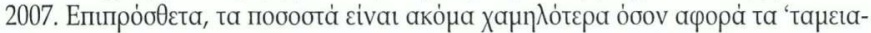

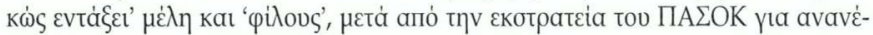

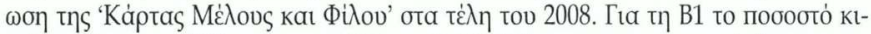

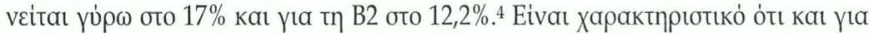

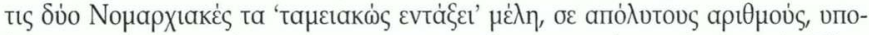

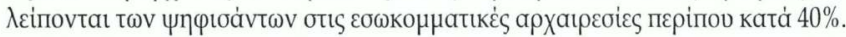

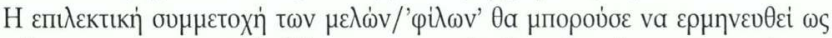

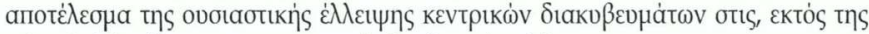

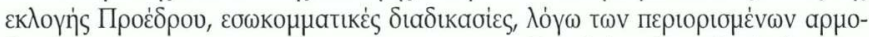

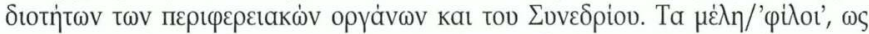

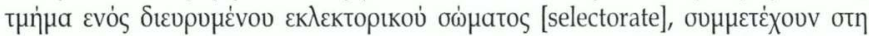

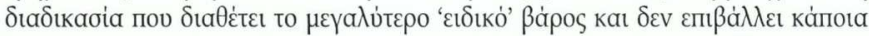

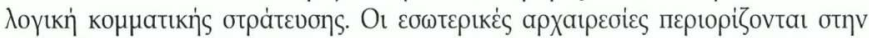

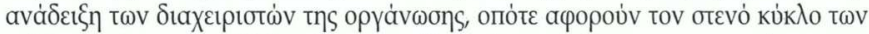

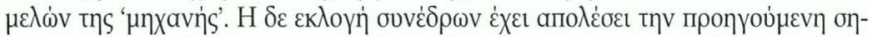

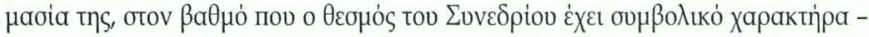

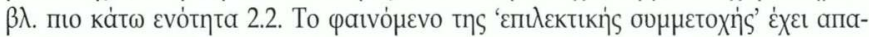

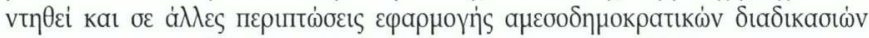

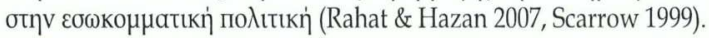

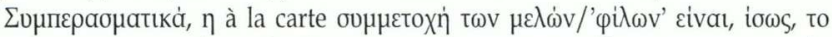

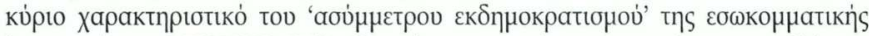

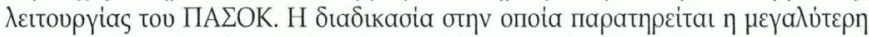

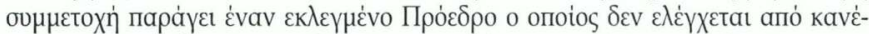

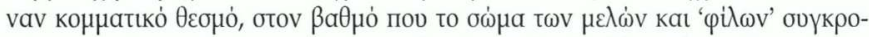

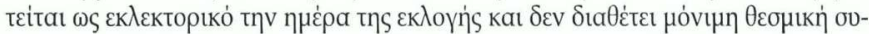

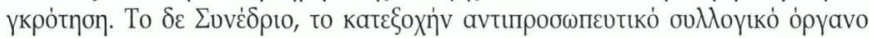

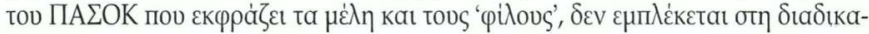

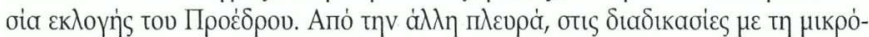

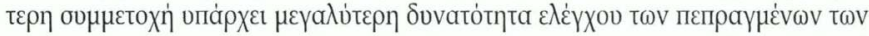

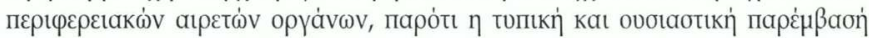

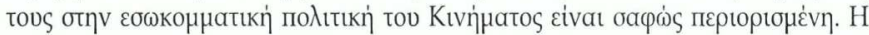

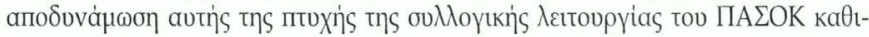




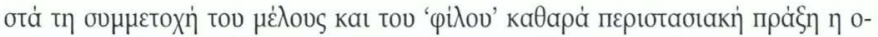

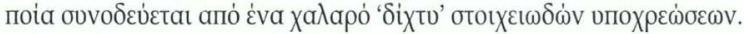

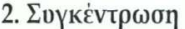

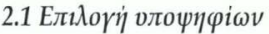

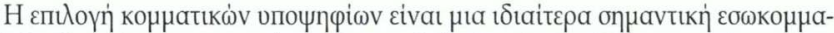

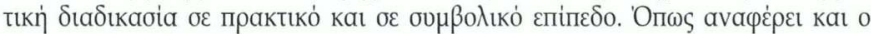

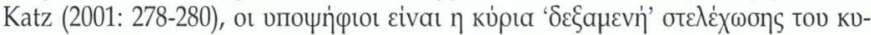

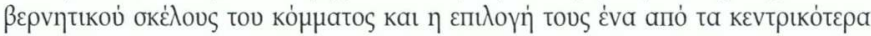

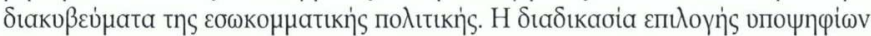

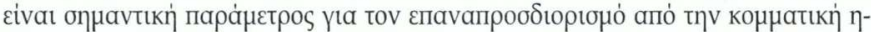

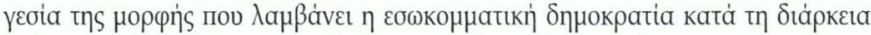

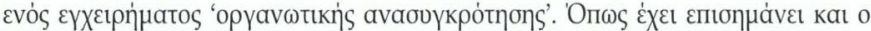

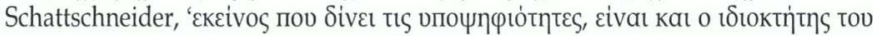

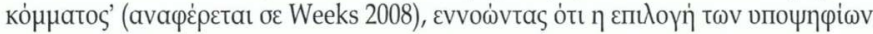

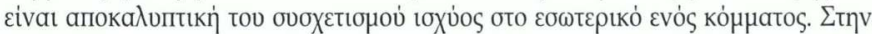
пвріпт

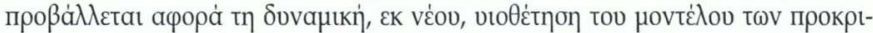

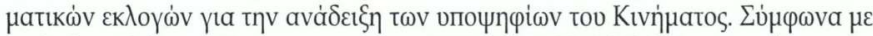

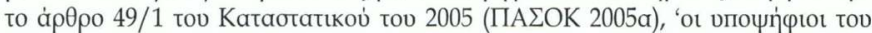

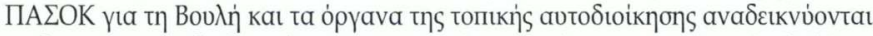

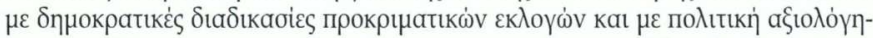

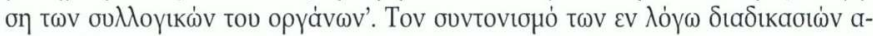

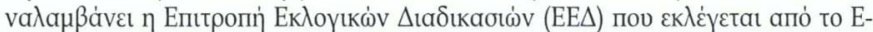

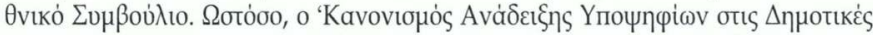

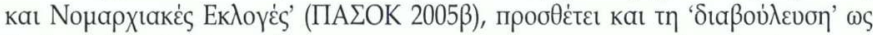

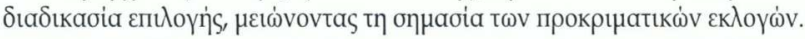

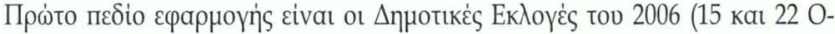

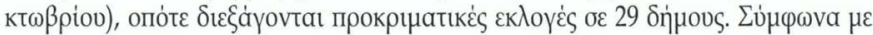

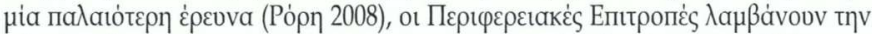

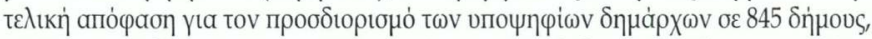

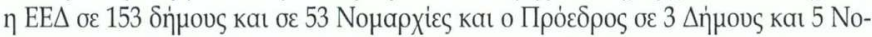

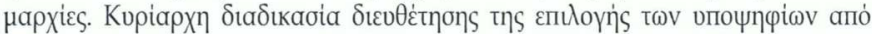

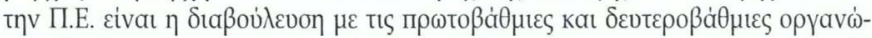

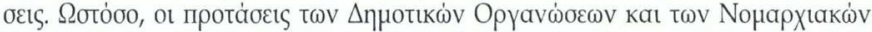

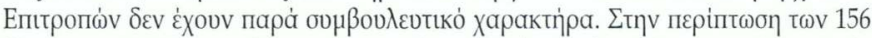

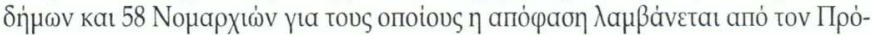




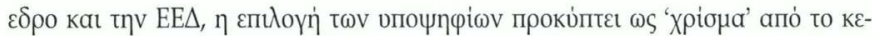

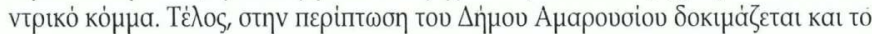

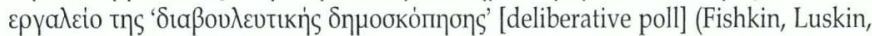
Panaretos et al. 2008).

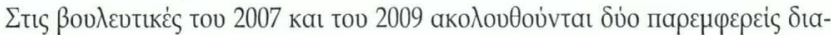

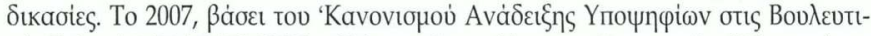

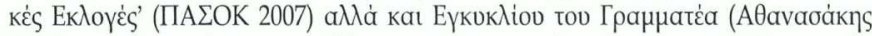

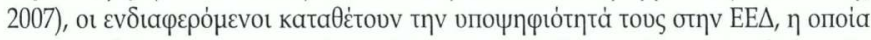

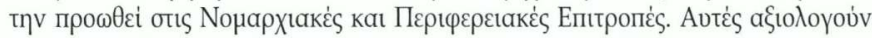

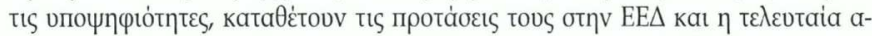

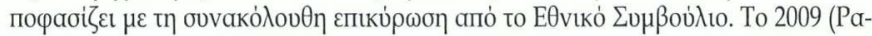

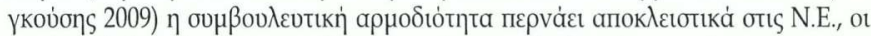

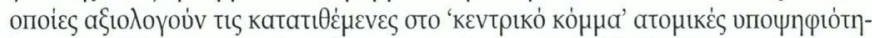

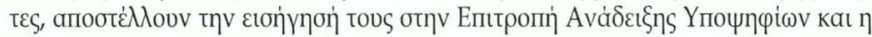

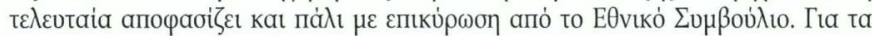

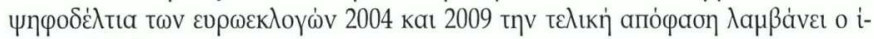

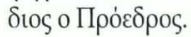

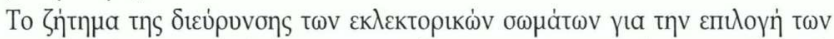

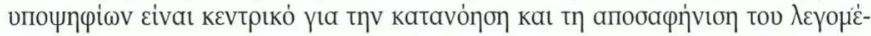

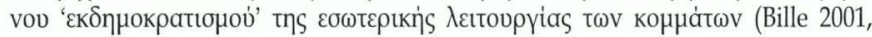

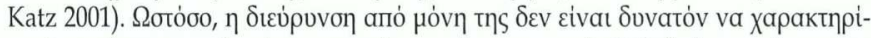

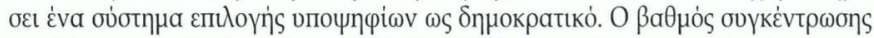

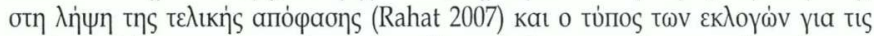

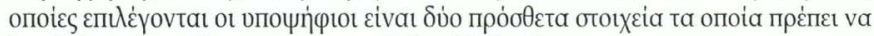

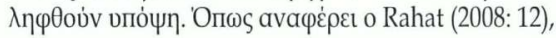

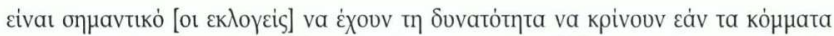

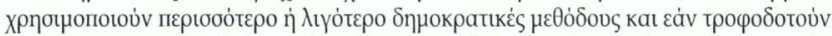

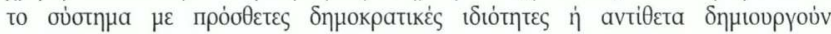
пров〉піната.

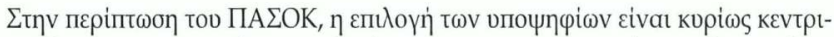

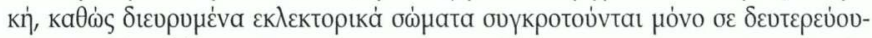

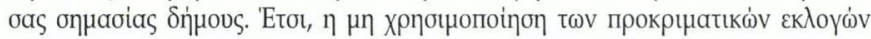

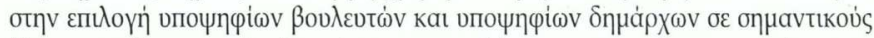

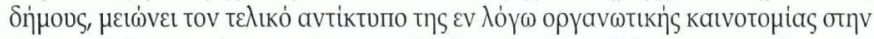

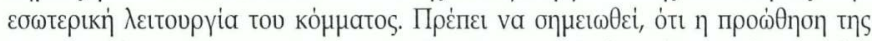

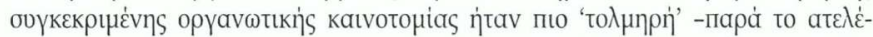

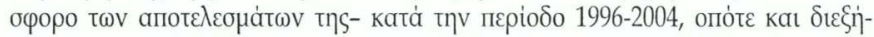

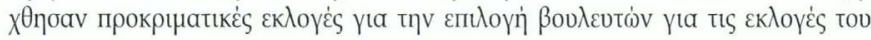




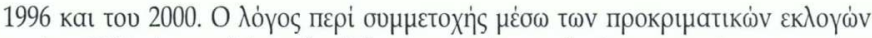

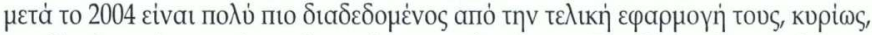

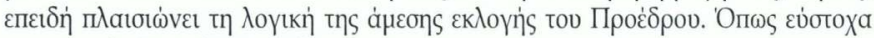
паратпреі о Katz (2001: 293),

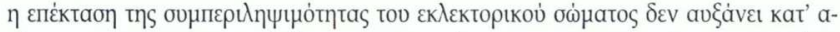

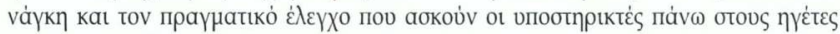

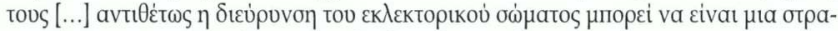

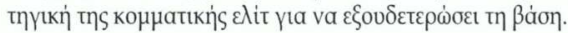

\section{2 Аларов}

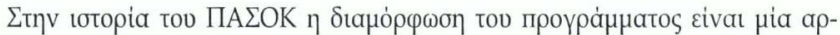

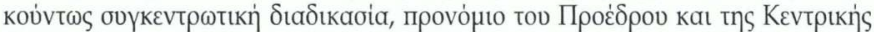

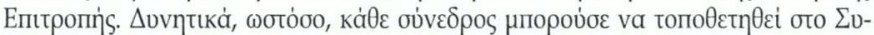

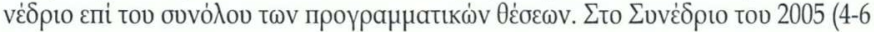

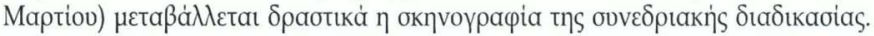

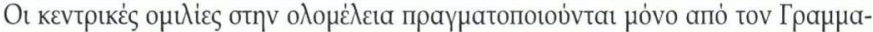

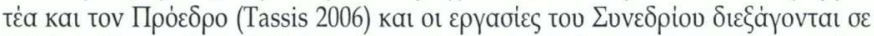

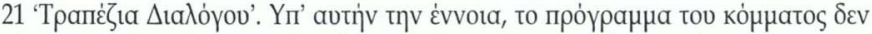

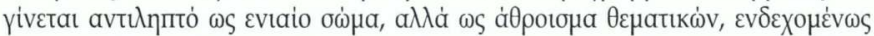

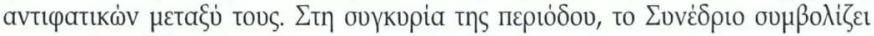

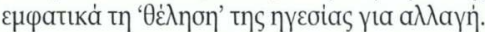

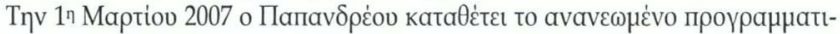

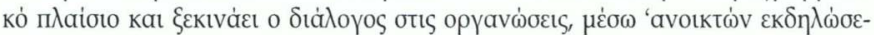

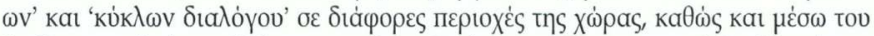

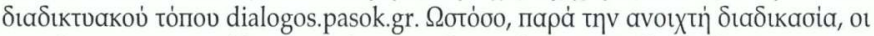

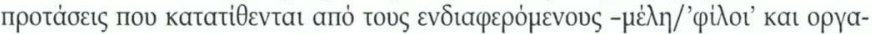

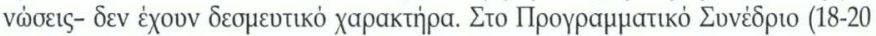

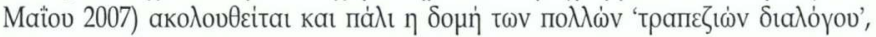

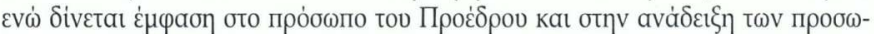

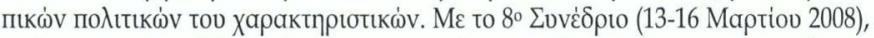

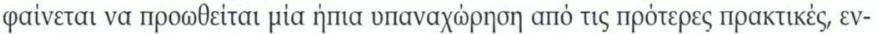

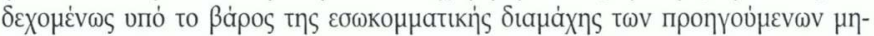

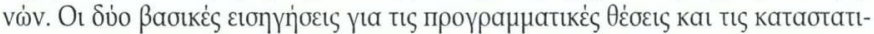

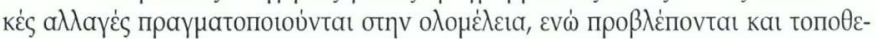
тท்

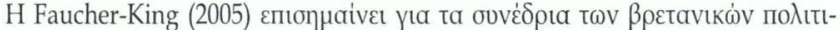

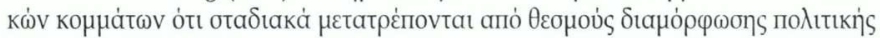




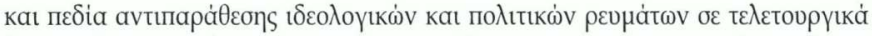

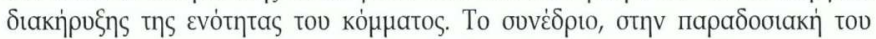

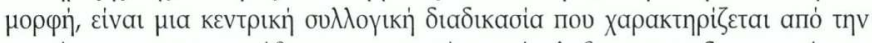

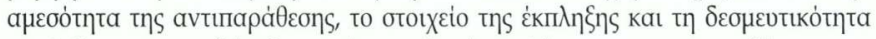
тฤ

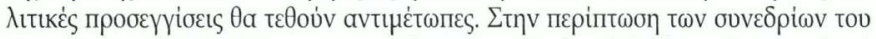

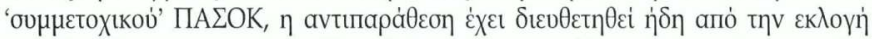

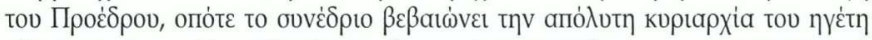

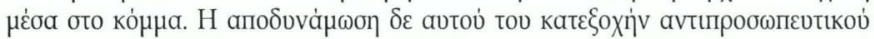

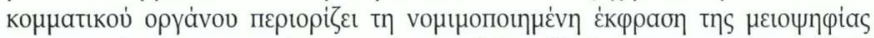

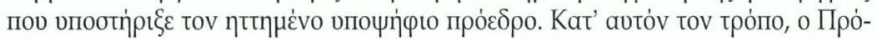

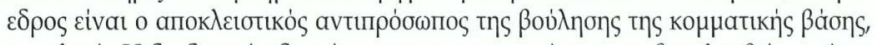

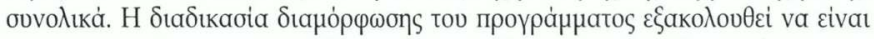

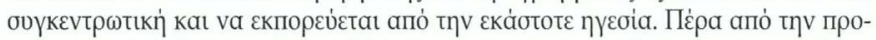

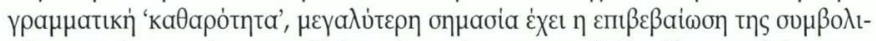

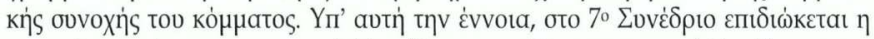

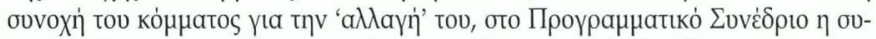

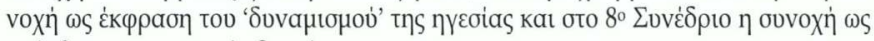

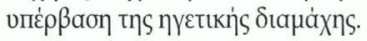

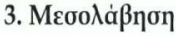

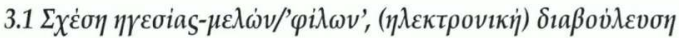

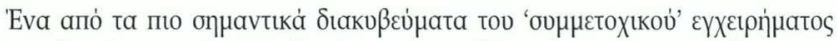

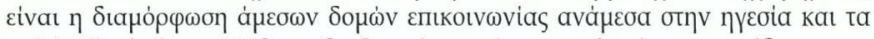

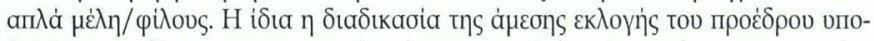

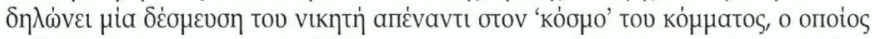

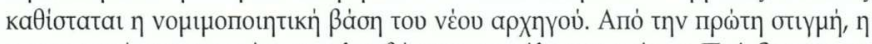

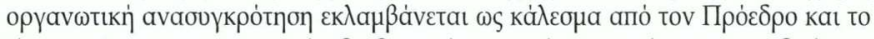

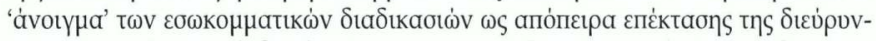

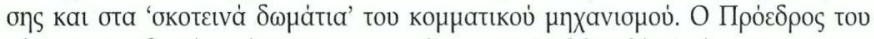

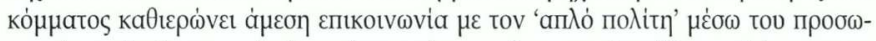

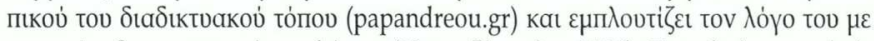

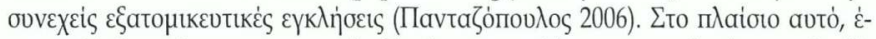

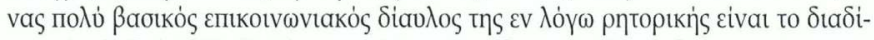

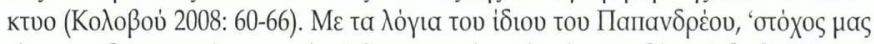

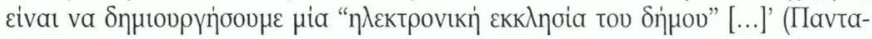

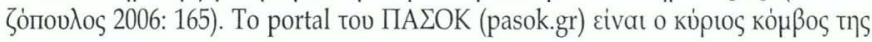




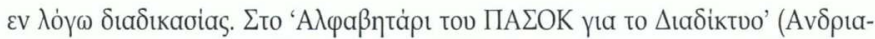

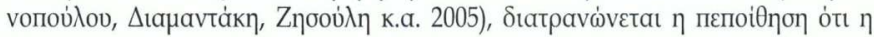

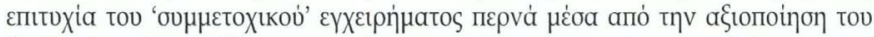

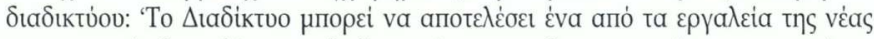

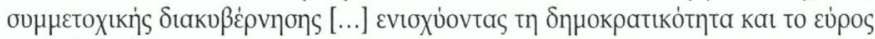
tᄁร по入ıтเкท่'s'.

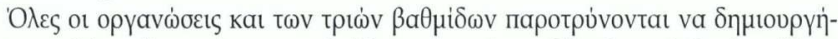

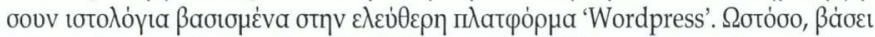

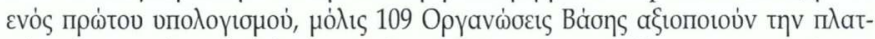

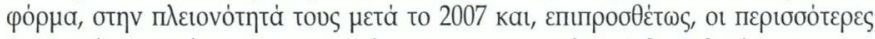

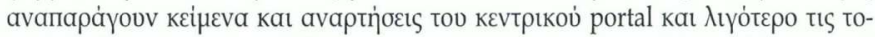

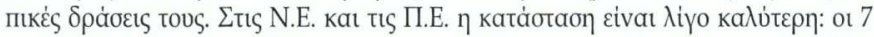

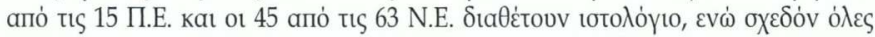

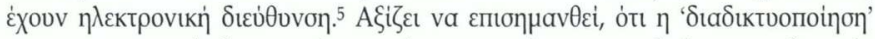

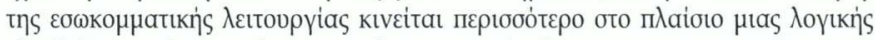

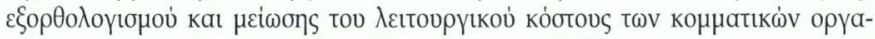

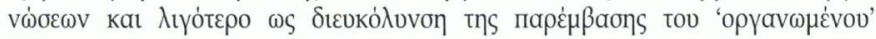

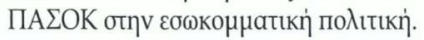

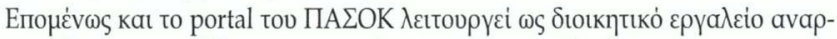

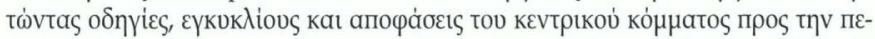

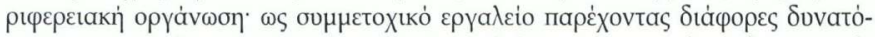

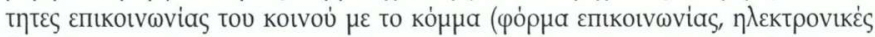

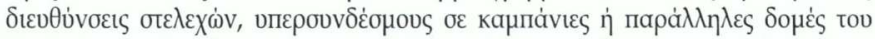

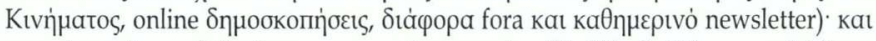

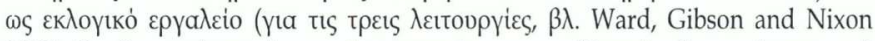

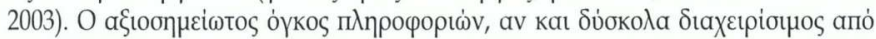

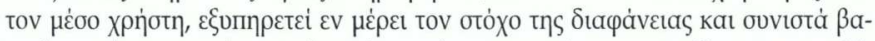
бเкó on $\mu \varepsilon i o$ ava

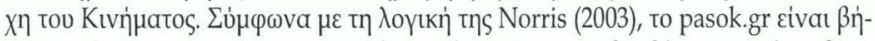

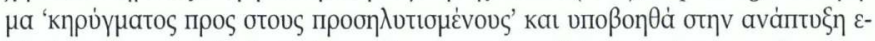

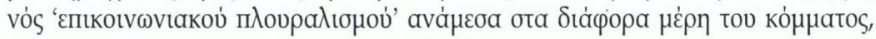

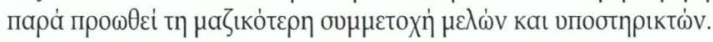

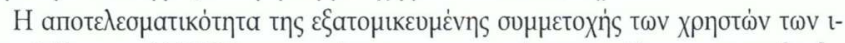

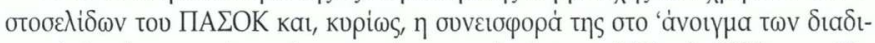

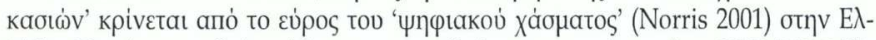

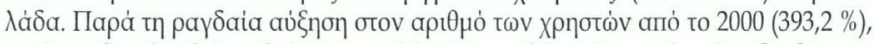
$\eta$ ๆ

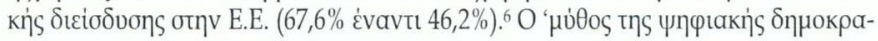




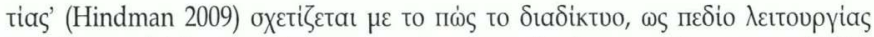

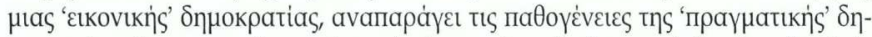

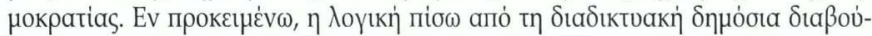

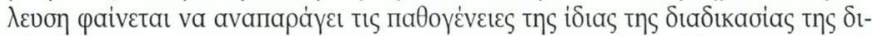

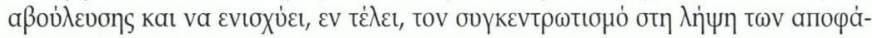

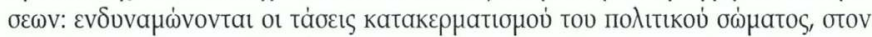

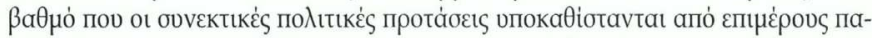

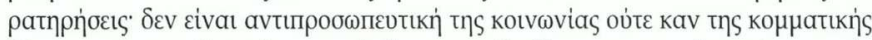

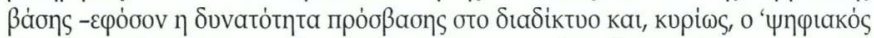

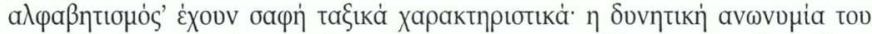

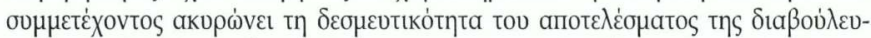

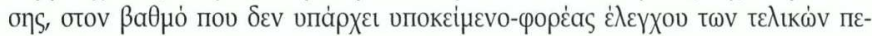

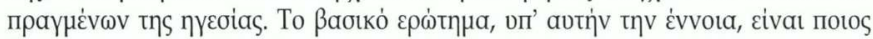

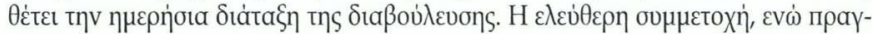

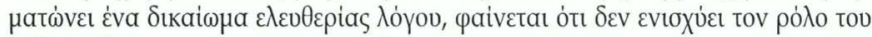

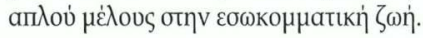

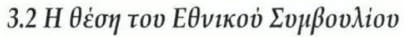

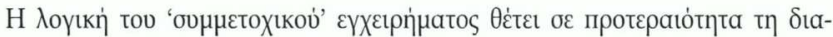

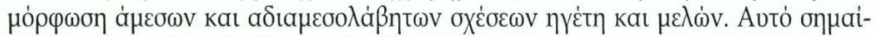

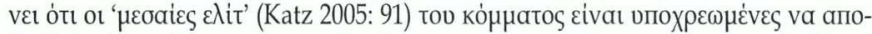

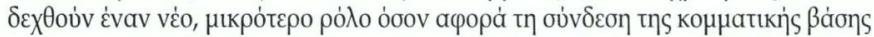

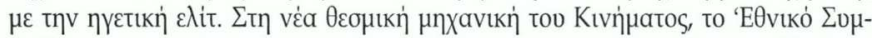

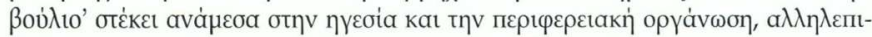

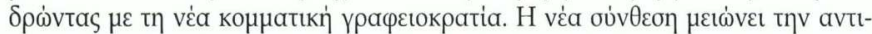

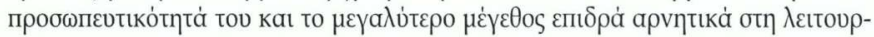

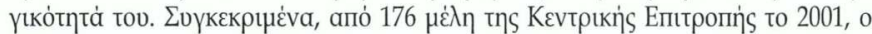

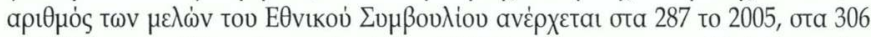

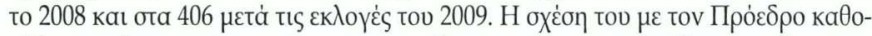

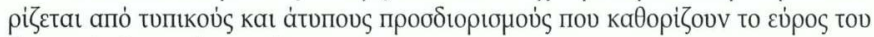

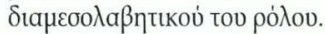

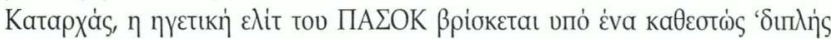

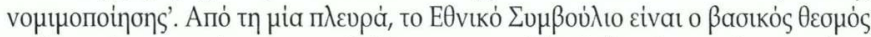

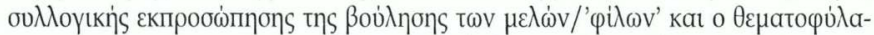

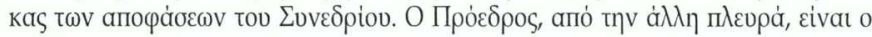

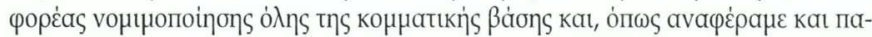

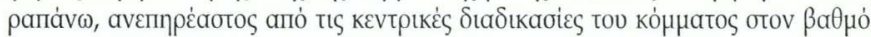

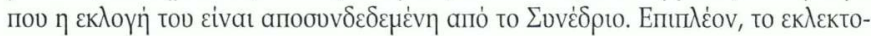




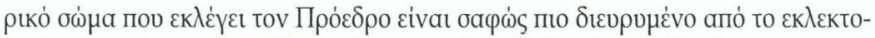

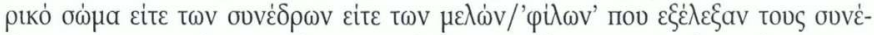

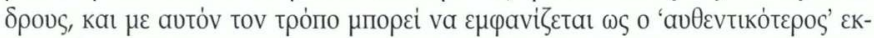

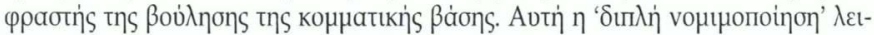

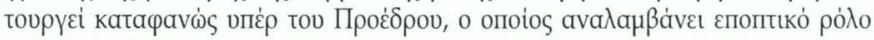

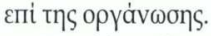

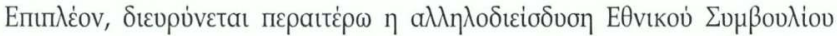

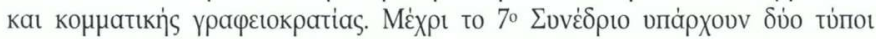

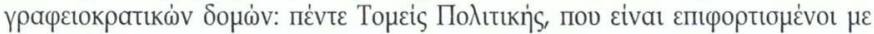

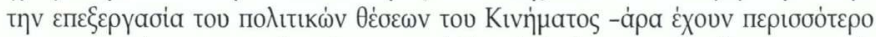

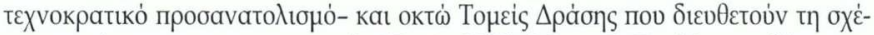

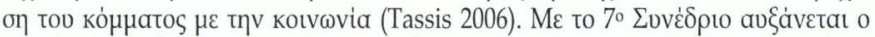

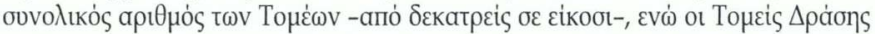

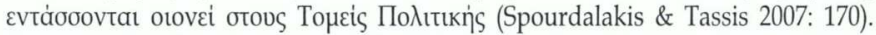

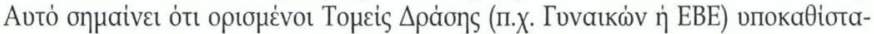

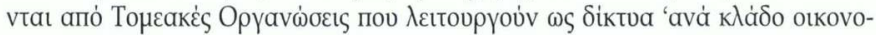

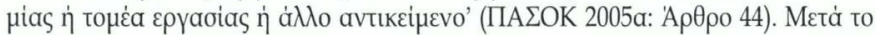

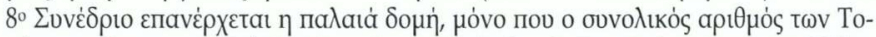

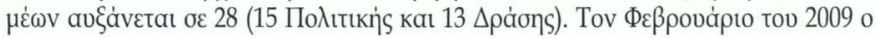

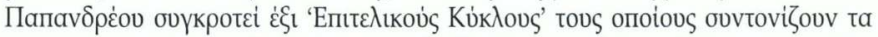

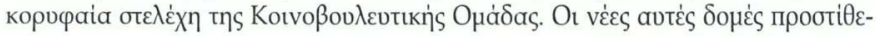

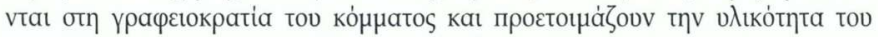

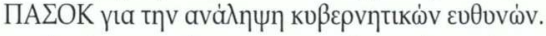

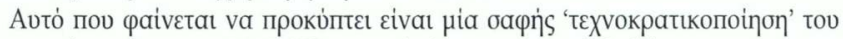

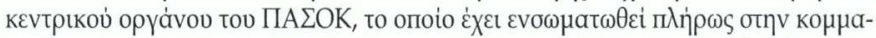

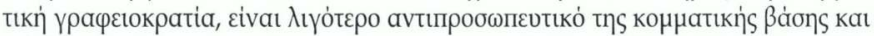

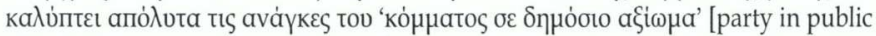

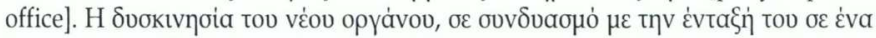

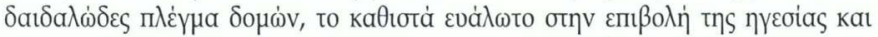

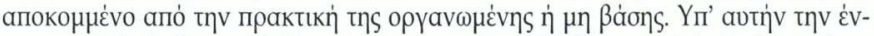

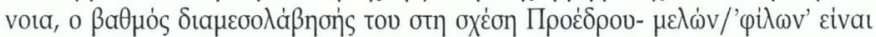

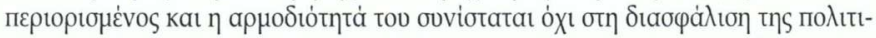

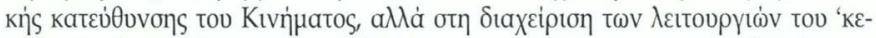

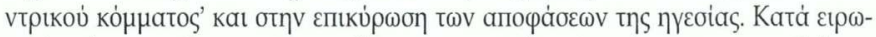

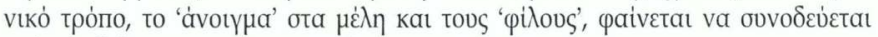

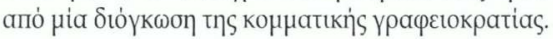




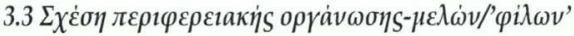

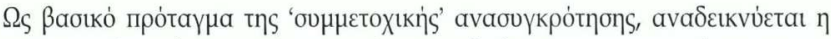

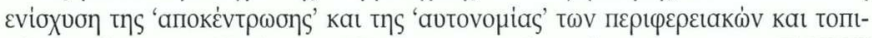

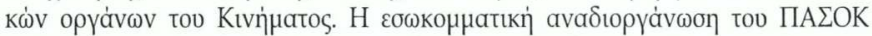

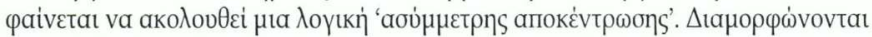

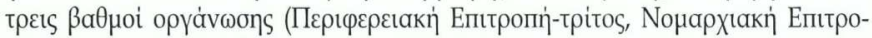

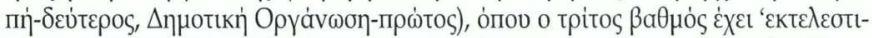

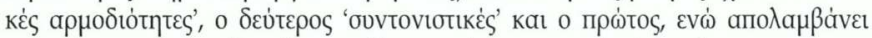

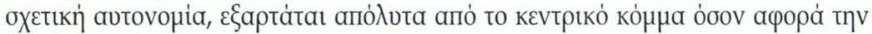
(ava)боүкроттпо̆ тор.

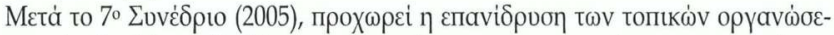

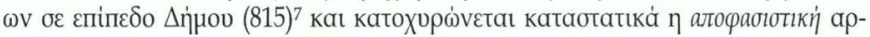
$\mu$

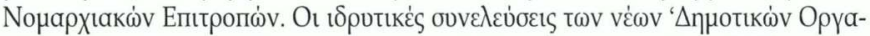

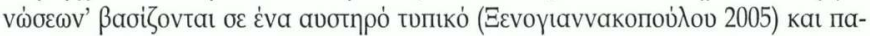

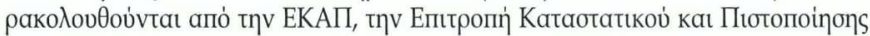

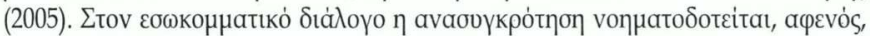

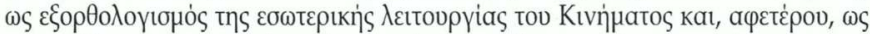

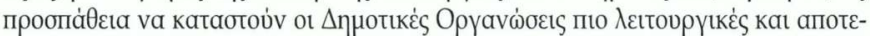

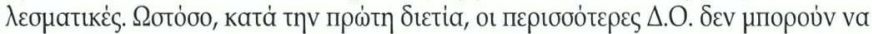

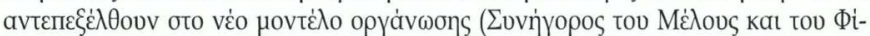
Nov 2007: 37-42).

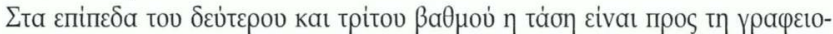

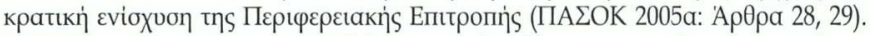

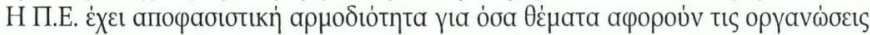

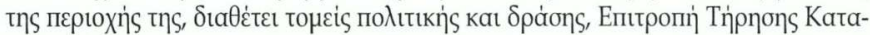

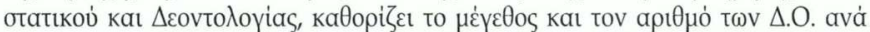

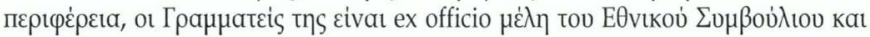

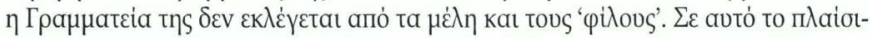

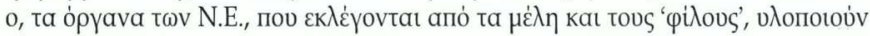

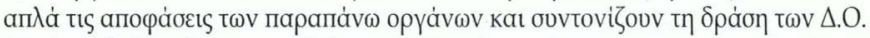

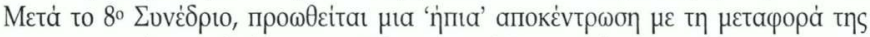

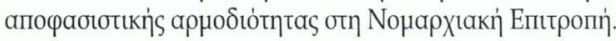

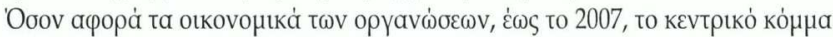

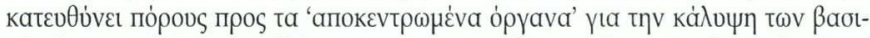

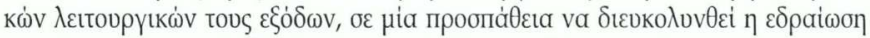

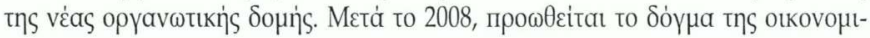




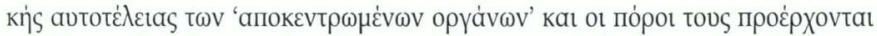

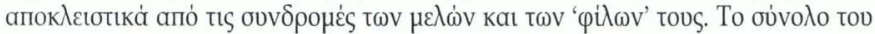

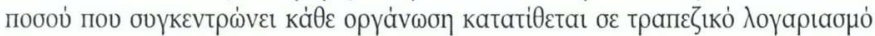

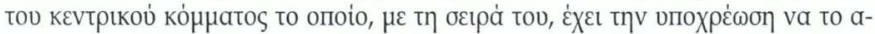

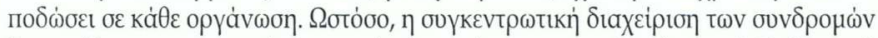

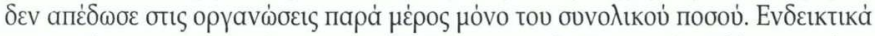

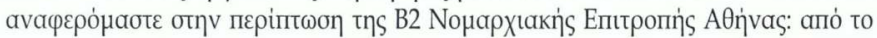

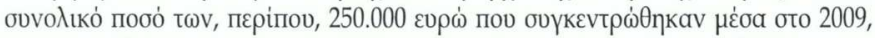

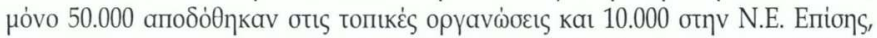

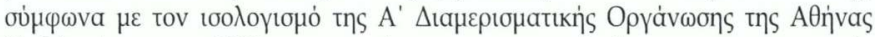

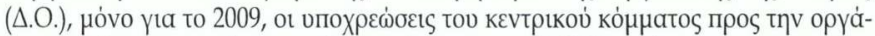

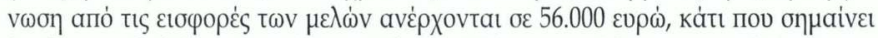

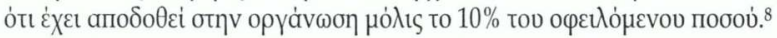

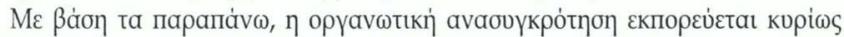

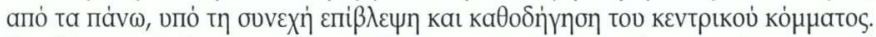

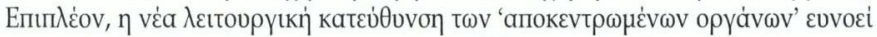

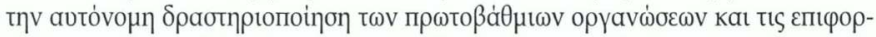

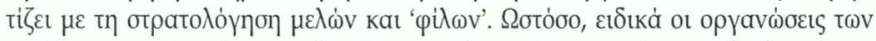

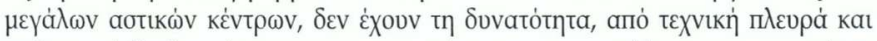

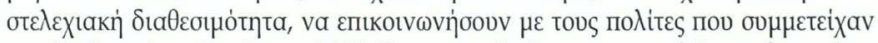

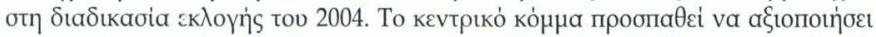

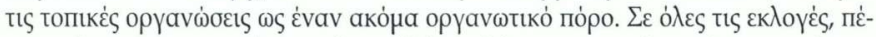

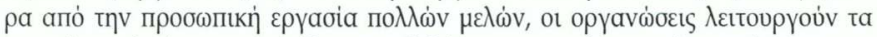

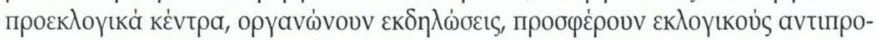

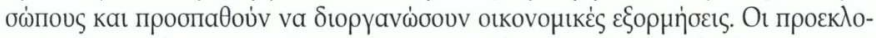

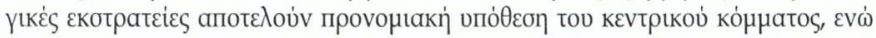

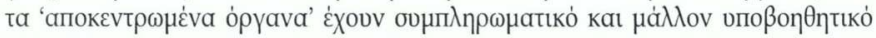

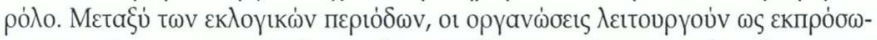

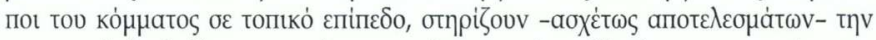

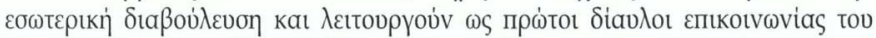

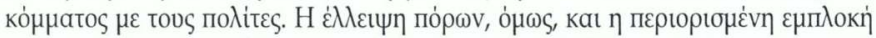

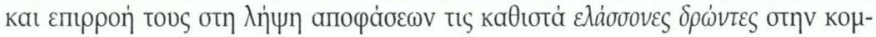
натікиं

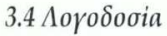

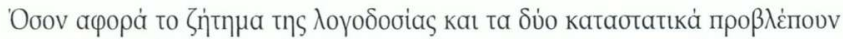

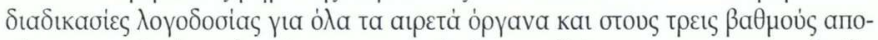

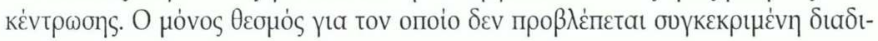




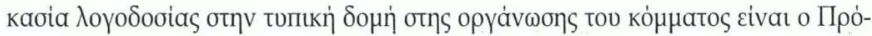

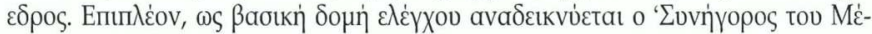

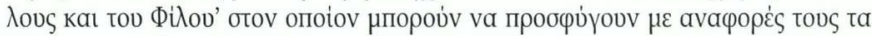

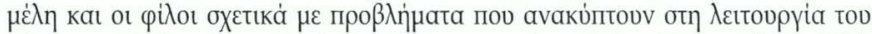

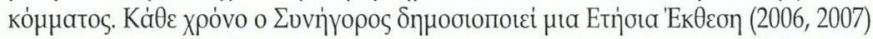

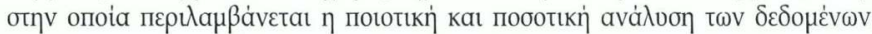

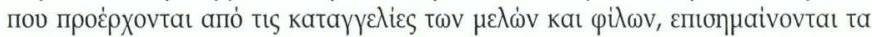

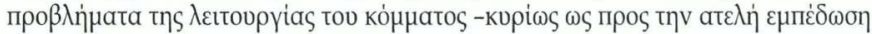

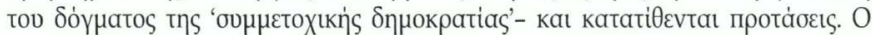

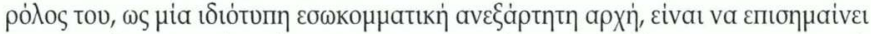

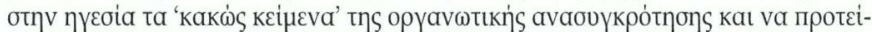

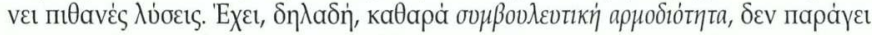

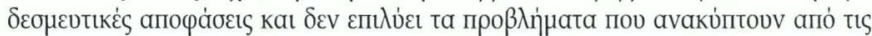

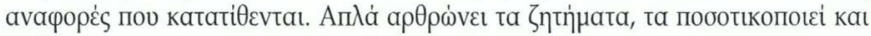

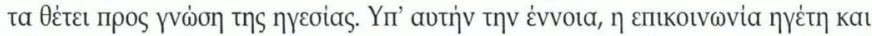

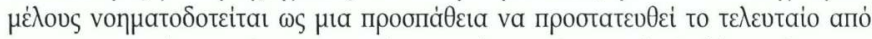

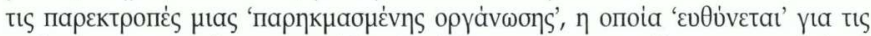

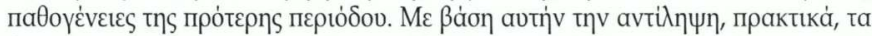

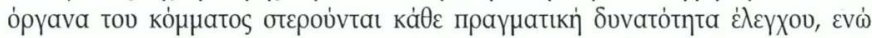

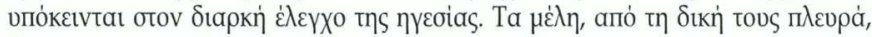

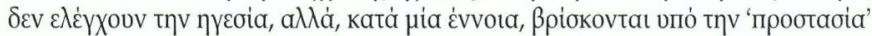

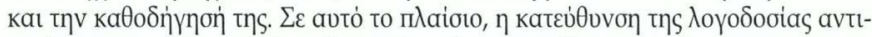

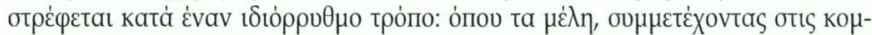

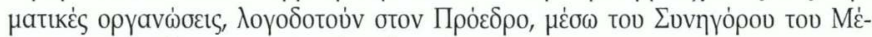

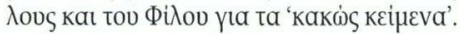

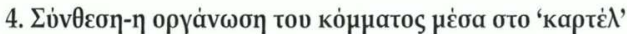

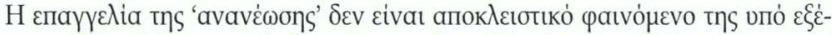

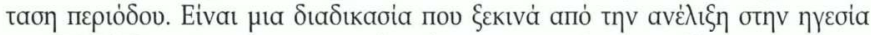

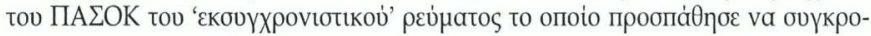

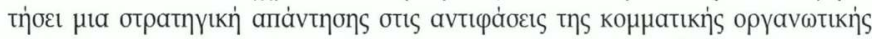

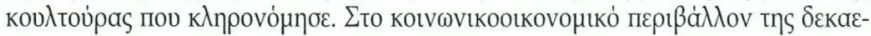

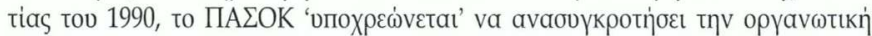

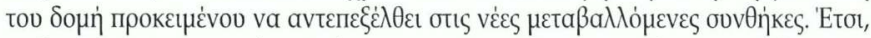

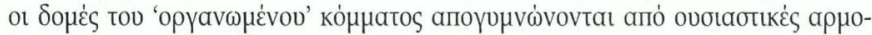

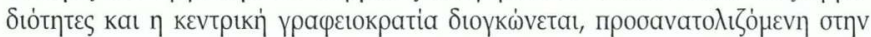

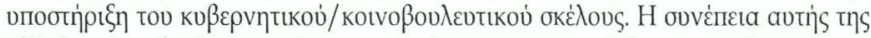

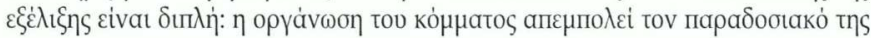




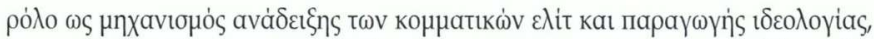

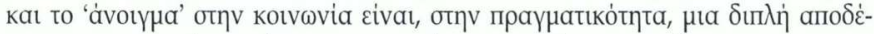

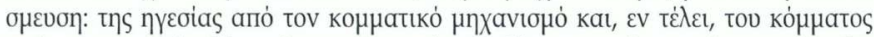

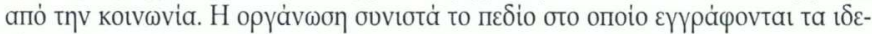

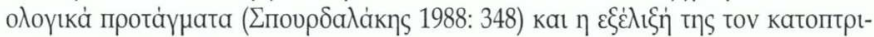

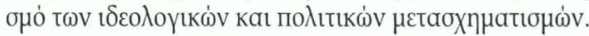

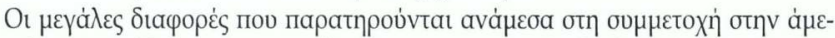

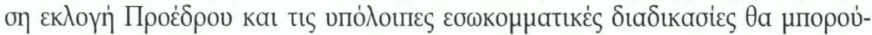

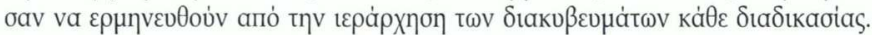

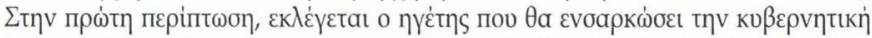

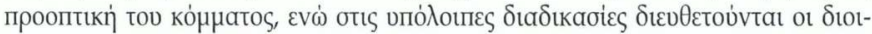

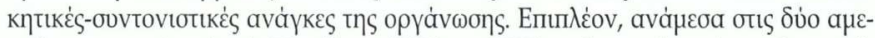

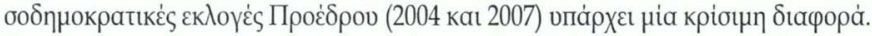

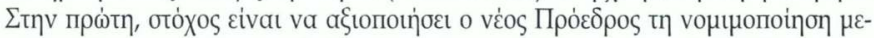

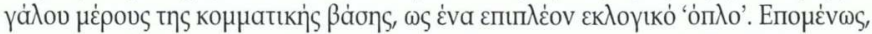

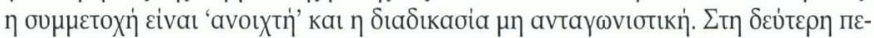

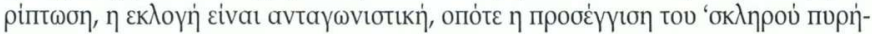

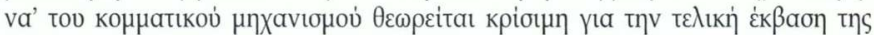
ava

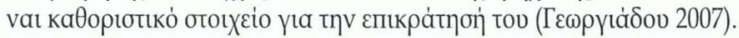

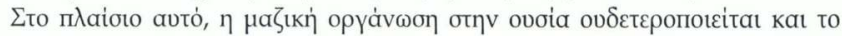

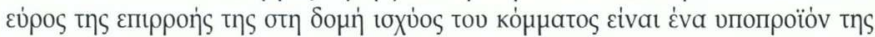

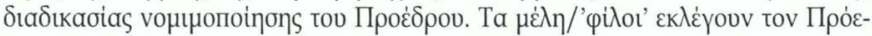

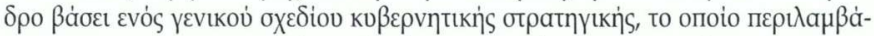

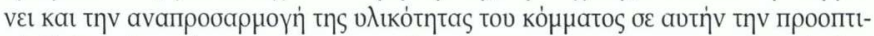

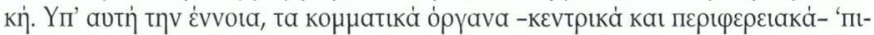

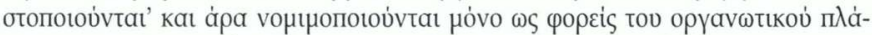

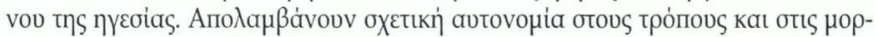

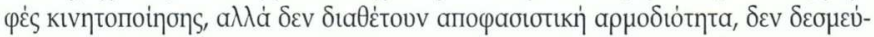

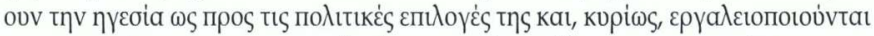

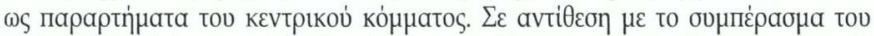

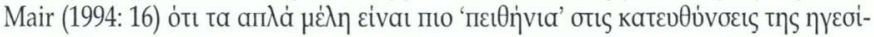

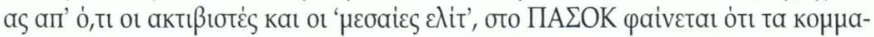

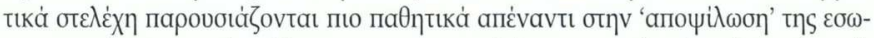

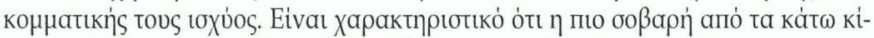

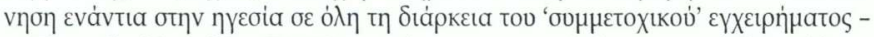

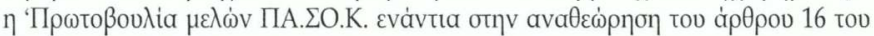

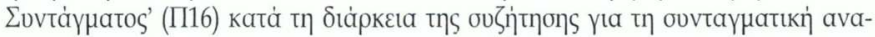




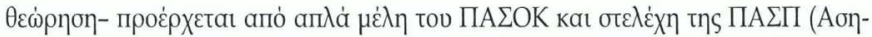

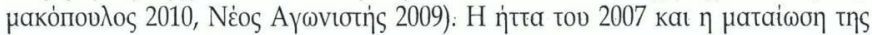

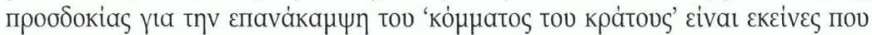

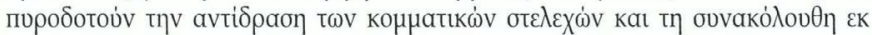

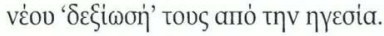

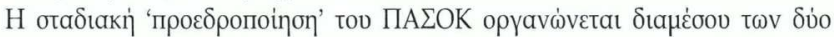

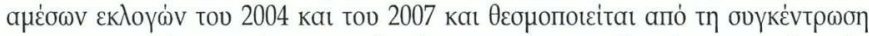

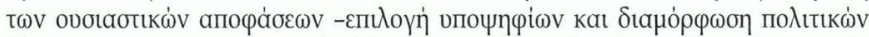

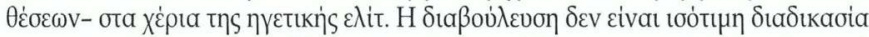

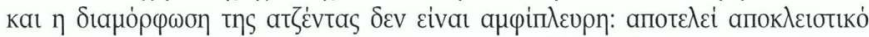

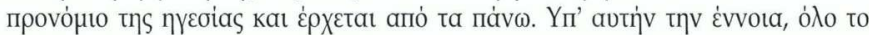

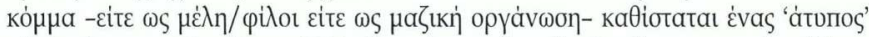

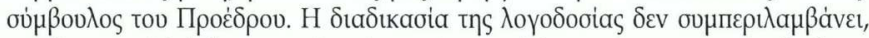

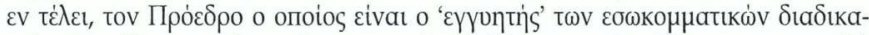

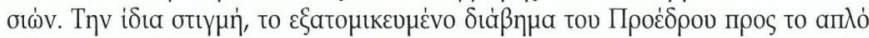

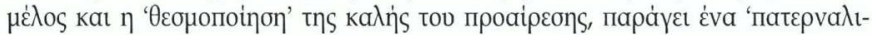

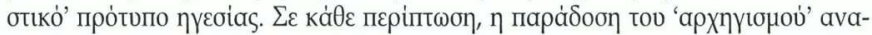

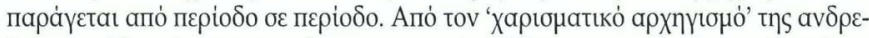

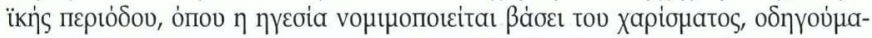

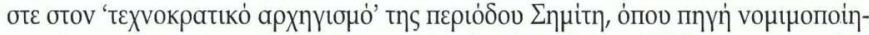

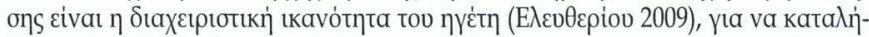

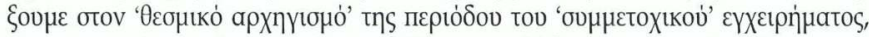

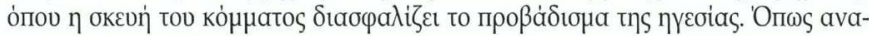

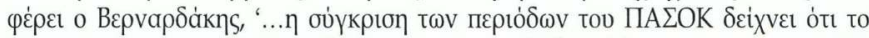

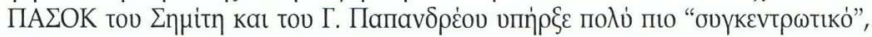

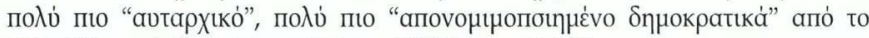

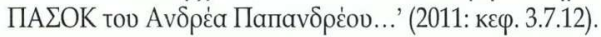

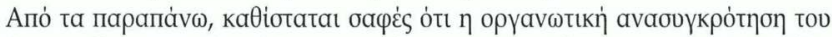

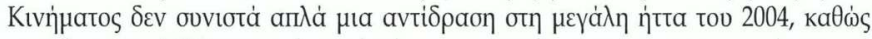

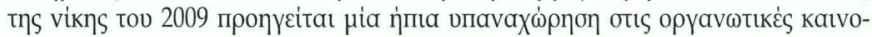

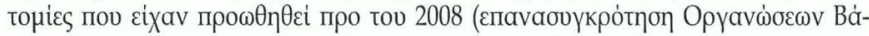

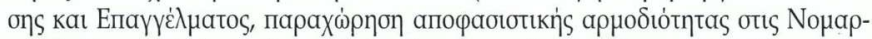

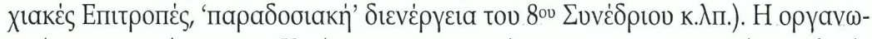

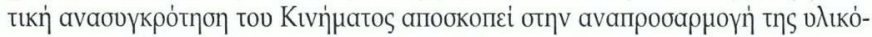

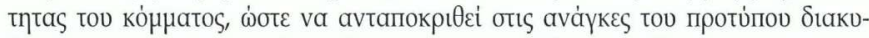

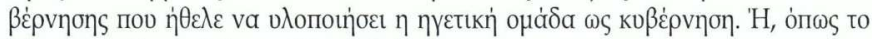

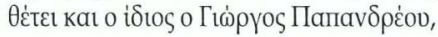




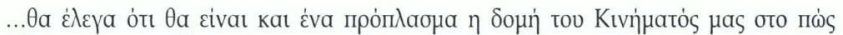

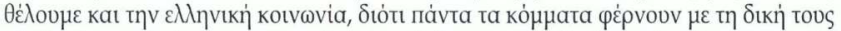

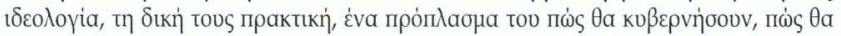

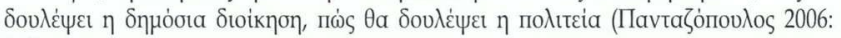
213).

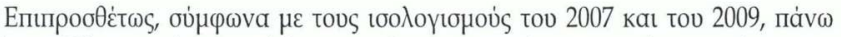

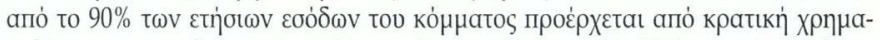

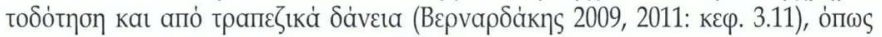

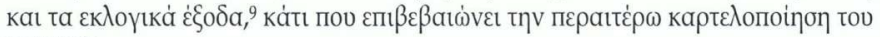
ПАЕОК.

\section{Avтi бонпера́онатоৎ}

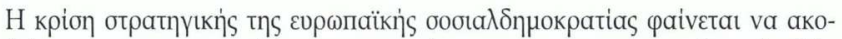

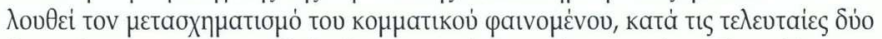

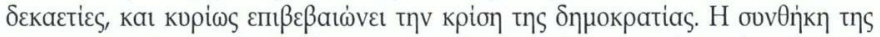

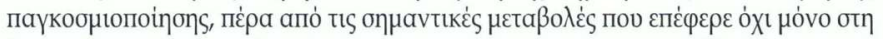

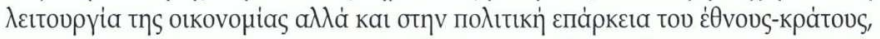

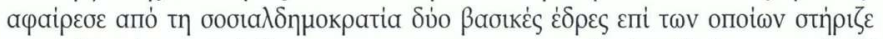

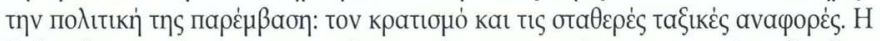

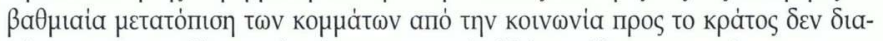

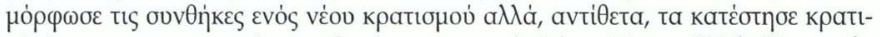

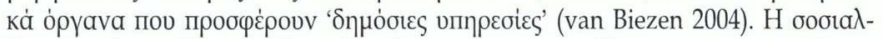

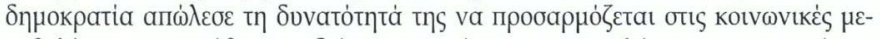

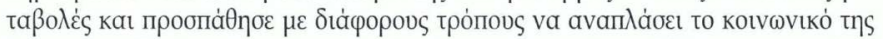

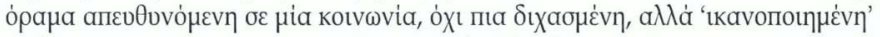

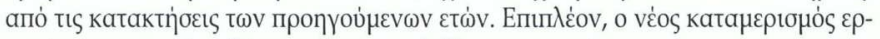

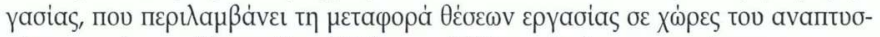

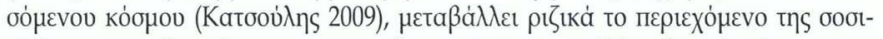

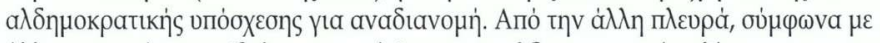

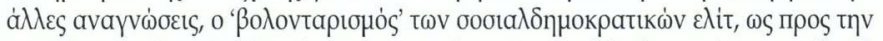

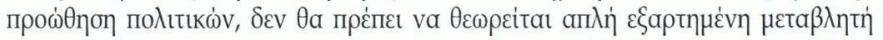

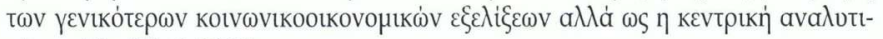

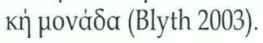

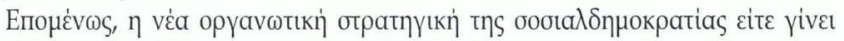

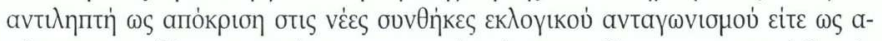

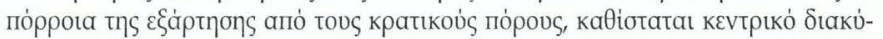

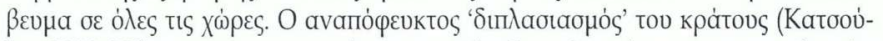

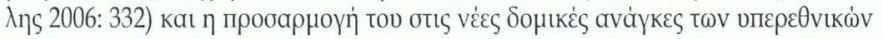




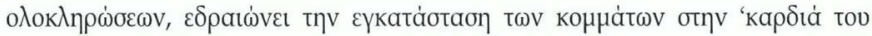

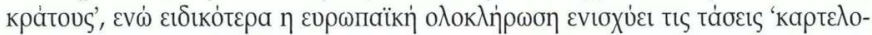

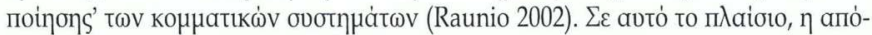

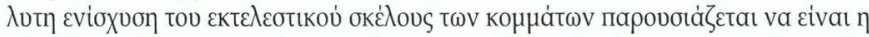

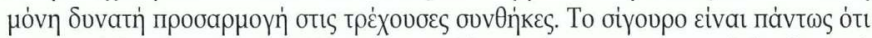

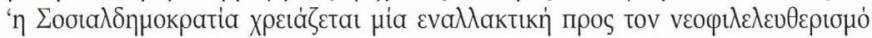

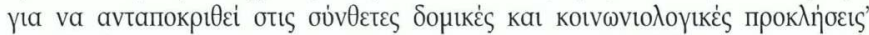

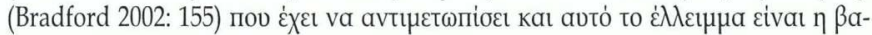

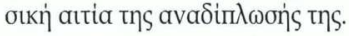

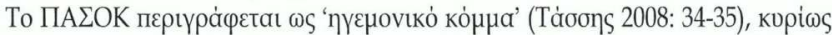

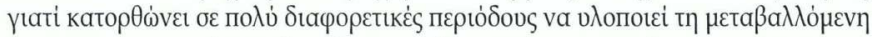

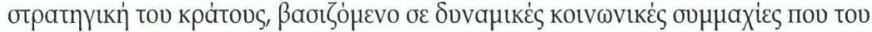

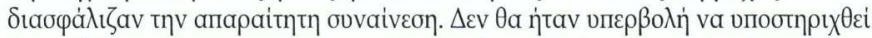

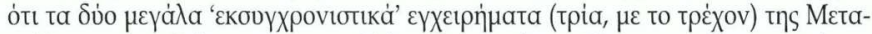

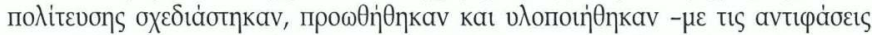

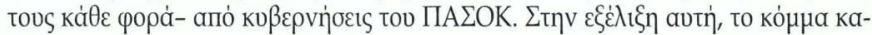

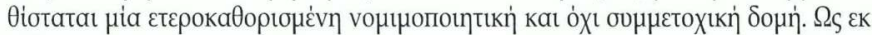

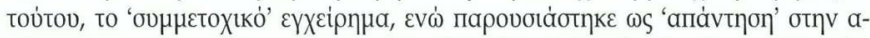

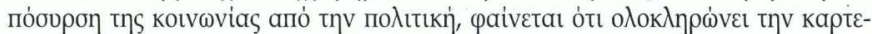

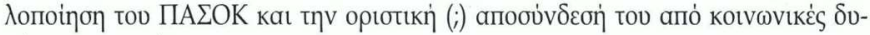

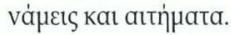

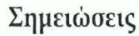

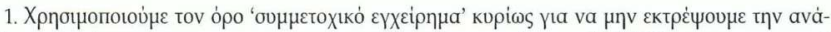

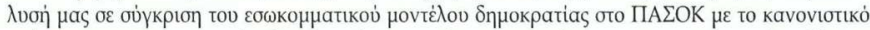

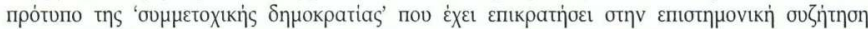

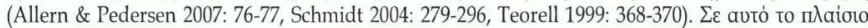

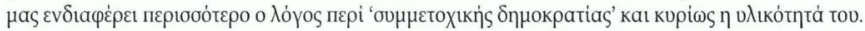

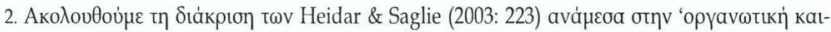

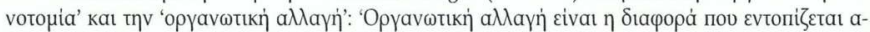

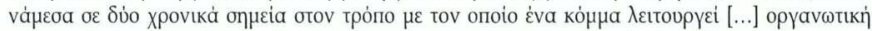

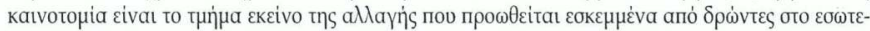

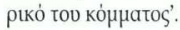

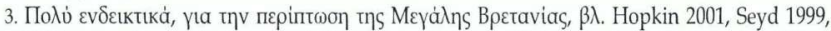

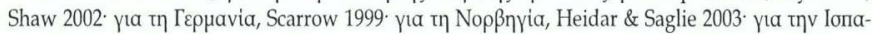

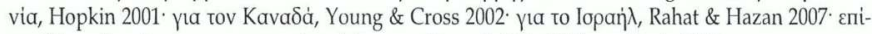

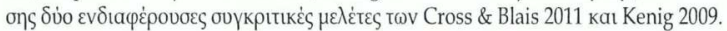

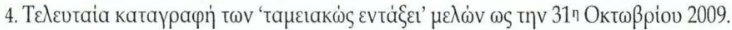




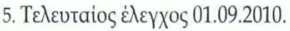

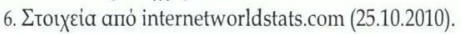

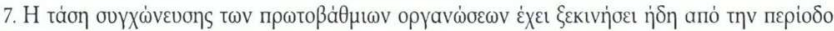

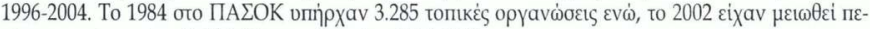

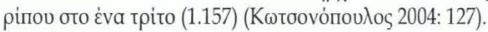

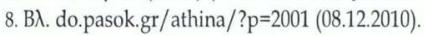

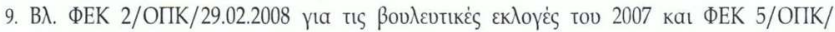

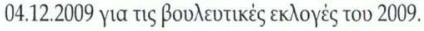

\section{Bıßıьораячіа}

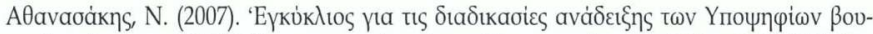

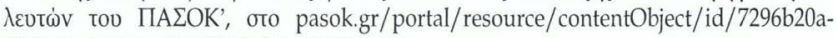
817f-45cd-96e2-df9dd35716a1 (08.12.2010).

Allern, E.H. \& K. Pedersen (2007). 'The impact of party organizational changes on democracy', West European Politics, 30, 1: 68-92.

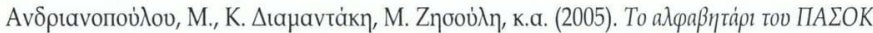

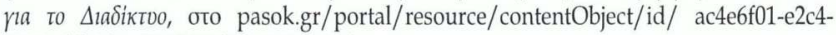
4962-abb3-b1a5123426f2 (08.12.2010).

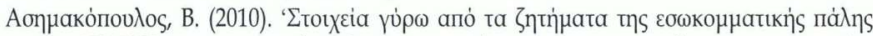

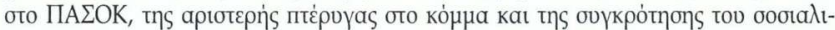

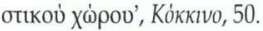

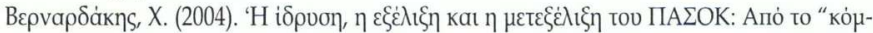

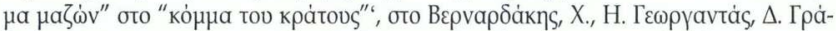

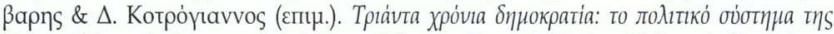

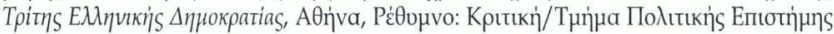

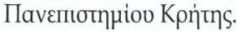

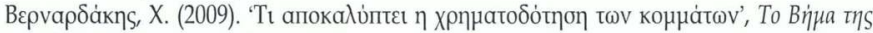
Кортакйร, $20 \Delta \varepsilon \kappa \varepsilon \mu \beta p i o v$.

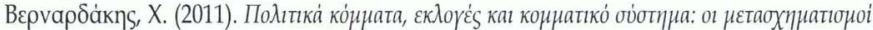

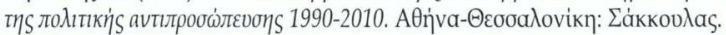

Bille, L., (2001). 'Democratizing a Democratic Procedure: Myth or Reality? Candidate Selection in Western European Parties 1960-1990', Party Politics, 7, 3: 363-380

Blyth, M. (2003). 'Globalization and the Limits of Democratic Choice: Social Democracy and the Rise of Political Cartelization', Internationale Politik und Gesellschaft, 3: 60-82.

Bradford, N. (2002). 'Renewing Social Democracy? Beyond the Third Way', Studies in Political Economy, 67: 145-161. 


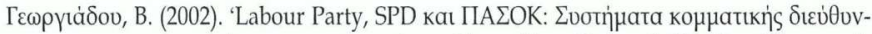

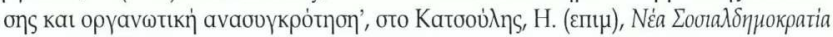

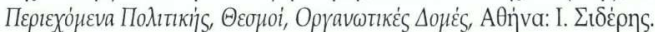

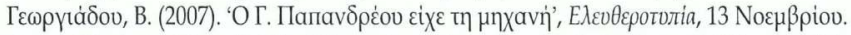

Cross, W. \& A. Blais (2011). 'Who selects the party leader?', Party Politics, published online before print, January 26.

Duverger, M. (1964[1951]). Political Parties, London: Methuen.

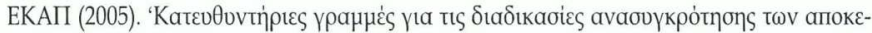

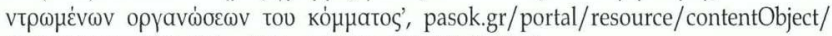
id/3452508b-d729-4b8e-ab78-edd4482ec20b (08.12.2010).

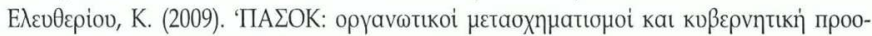
птккиं, Елохй, 4 Октөßріоо.

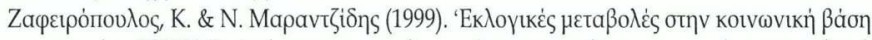

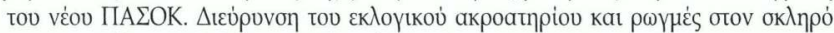

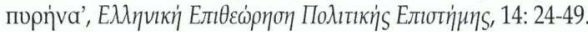

Faucher-King, F. (2005). Changing Parties: an Anthropology of British Political Party Conferences, London, New York: Routledge.

Fishkin, J., R. Luskin, J. Panaretos, et al. (2008). 'Returning Deliberative Democracy to Athens: Deliberative Polling for Candidate Selection', paper presented at the Annual Meeting of the American Political Science Association, Boston, August 28 th

Heidar, K. and J. Saglie (2003). 'Predestined Parties? Organizational Change in Norwegian Political Parties', Party Politics, 9, 2: 219-239.

Hindman, M. (2009). The Myth of Digital Democracy, Princeton, Oxford: Princeton University Press.

Hopkin, J. (2001). 'Bringing the Members Back In? Democratizing Candidate Selection in Britain and Spain', Party Politics, 7, 3: 343-361.

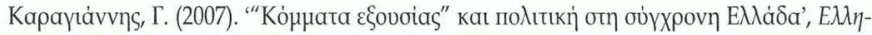

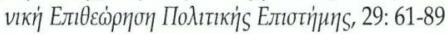

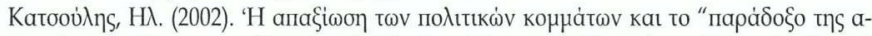

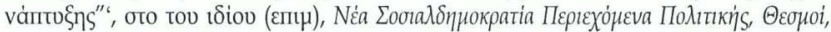

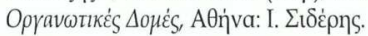

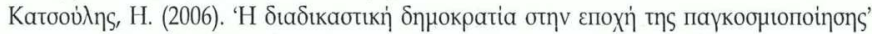

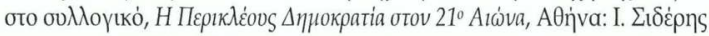

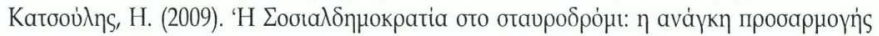

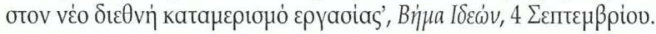

Katz, R. S., (2001). 'The Problem of Candidate Selection and Models of Party Democracy', Party Politics, 7, 3: 277-296. 
Katz, R. (2005). 'The Internal Life of Parties', бто Luther, K.R. \& F. Müller-Rommel (eds), Political Parties in the New Europe: Political and Analytical Challenges, Oxford: Oxford University Press.

Katz, R.S. and P. Mair (1995). 'Changing Models of Party Organization and party Democracy: The Emergence of the Cartel party', Party Politics, 1, 1:5-28

Katz, R.S. \& P. Mair (2002). 'The Ascendancy of the Party in Public Office: Party Organizational Change in Twentieth-Century Democracies' in Gunther R., J.R. Montero \& J. Linz (eds). Political Parties. Old Concepts and New Challenges, Oxford: Oxford University Press.

Katz, R., P. Mair, L. Bardi et al. (1992). 'The membership of political parties in European democracies, 1960-1990', European Journal of Political Research, 22, 3: 329-345.

Kenig, O. (2009). 'Democratization of party leadership selection: Do wider selectorates produce more competitive contests?', Electoral Studies, 28, 2: 240-247.

Kitschelt, H. (2000). 'Citizens, politicians, and party cartellization: Political representation and state failure in post-industrial democracies', European Journal of Political Research, 37, 2: 149-179.

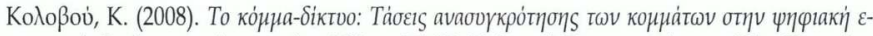

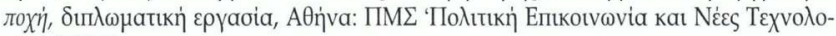
үiєs'/ ЕКПА.

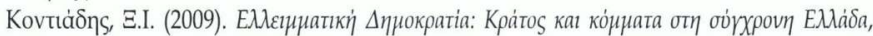

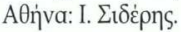

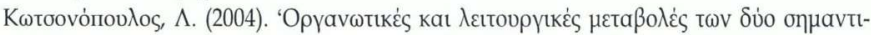

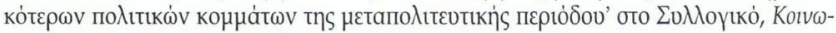

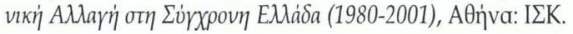

Mair, P. (1994). 'Party Organizations: From Civil Society to the State', бл Katz, R.S. \& P. Mair (eds) How Parties Organize: Change and Adaptation in Party Organizations in Western Democracies, London: Sage.

Mair, P. \& I. van Biezen (2001). 'Party Membership in Twenty European Democracies 1980-2000', Party Politics, 7, 1: 5-21.

Moschonas, G. (2001). 'The path of modernization: PASOK and European integration', Journal of Southern Europe and the Balkans, 3, 1: 11-24.

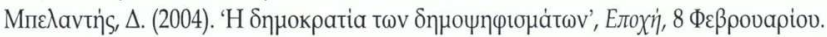

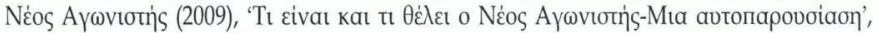
oto neos-agonistis.blogspot.com/2009/03/blog-post.html (08.12.2010).

Norris, P. (2001). Digital Divide: Civic Engagement, Information Poverty, and the Internet Worldwide, Cambridge, New York: Cambridge University Press.

Norris, P. (2003). 'Preaching to the Converted?: Pluralism, Participation and Party Websites', Party Politics, 9, 1: 21-45. 


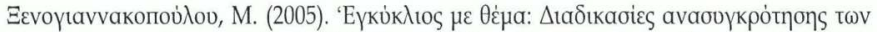

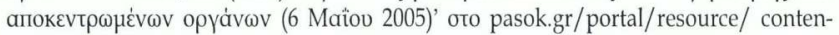
tObject/id/9ce4f9b2-c8b2-4a4d-80d9-75e001e4186d (08.12.2010)

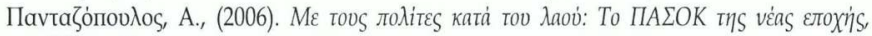
A $\operatorname{rina:~Eoria.~}$

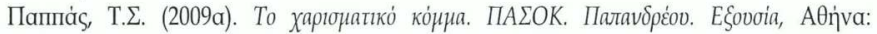
Пата́knฺ.

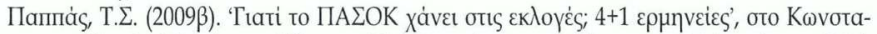

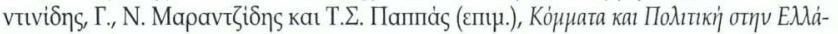

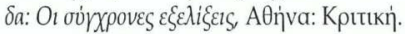

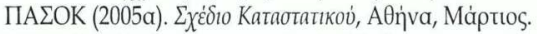

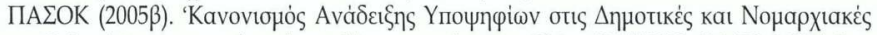
Ekloyés' oto pasok.gr/portal/resource/contentObject/id/40f23eff-1683-4457-b6eec50d6b36a422 (08.12.2010)

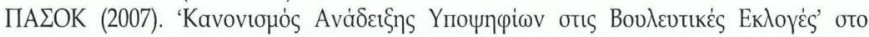
pasok.gr/portal/resource/contentObject/id/0b471906-5ade-467a-beee-77280332b2fb (08.12.2010)

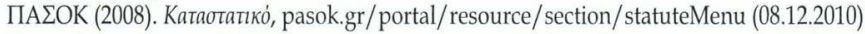

Poguntke, T. (1996). 'Anti-party sentiment-Conceptual thoughts and empirical evidence: Explorations into a minefield', European Journal of Political Research, 29, 3:319-344.

Poguntke, T. \& P. Webb (2007). 'The Presidentialization of Politics in Democratic Societies: A Framework for Analysis' oтo Poguntke, T. \& P. Webb (eds), The Presidentialization of Politics: A Comparative study of Modern Democracies, Oxford, New York: Oxford University Press.

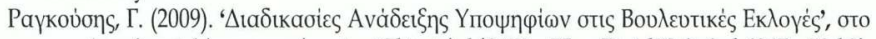
pasok.gr/portal/resource/contentObject/id/8472ca75-ae71-4d78-9a6c-b6967ac53d6f (08.12.2010).

Rahat, G (2007). 'Candidate Selection: The Choice Before the Choice', Journal of Democracy, $18,1: 157-170$.

Rahat, G (2008). 'Which Candidate Selection Method Is More Democratic?', Working Paper, Center for the Study of Democracy, University of California, Irvine.

Rahat, G. \& R.Y. Hazan (2007). 'Political participation in party primaries: increase in quantity, decrease in quality?' oto Zittel, T. \& D. Fuchs (eds), Participatory Democracy and Political Participation: can participatory engineering bring citizens back in?, London and New York: Routledge/ECPR.

Raunio, T. (2002). 'Why European Integration Increases Leadership Autonomy Within Political Parties', Party Politics, 8, 4: 405-422.

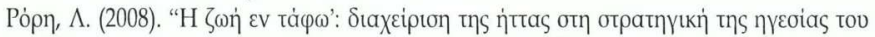

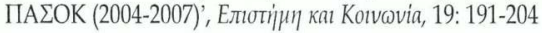




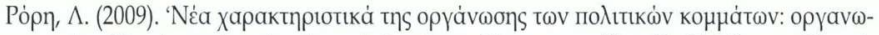

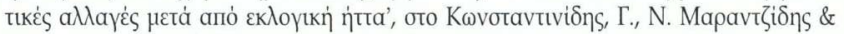

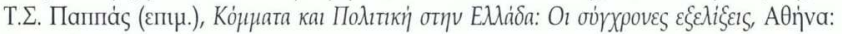
Kрtтtкn่.

Sartori, G. (2005[1976]). Parties and Party Systems: A Framework for Analysis, Colchester: ECPR Press.

Scarrow, S. (1996). Parties and Their Members: Organizing for Victory in Britain and Germany, Oxford, New York: Oxford University Press.

Scarrow, S. (1999). 'Parties and the Expansion of Direct Democracy. Who Benefits?', Party Politics, 5, 3: 341-362

Scarrow, S \& B. Gezgor (2010). 'Declining memberships, changing members? European political party members in a new era', Party Politics, 16, 6: 823-843

Seyd, P. (1999). 'New Parties/New Politics? A Case Study of the British Labour Party', Party Politics, 5, 3: 383-405.

Shaw, E. (2002). 'New Labour in Britain: New Democratic Centralism?', West European Politics, 25, 3: 147-70.

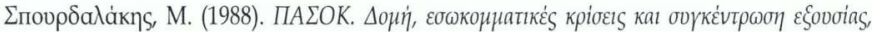

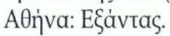

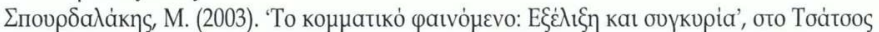

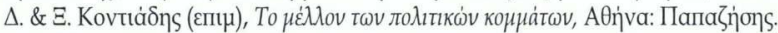

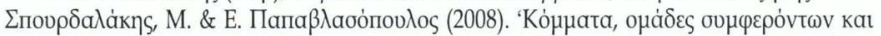

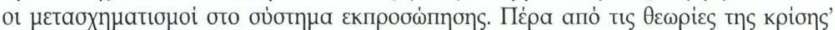

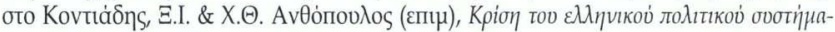

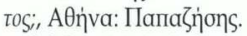

Spourdalakis, M. \& C. Tassis (2007). 'Party Change in Greece and the Vanguard Role of PASOK', oto Bosco, A. \& L. Morlino (eds), Party Change in Southern Europe, London, New York: Routledge.

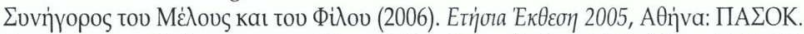

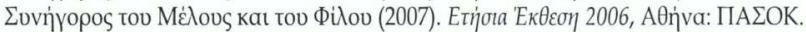

Tassis, C. (2006). 'The $7^{\text {th }}$ Congress of PASOK (2005): 'Towards an "open" party?', paper presented at the $56^{\text {th }}$ Annual PSA Conference, Reading, UK.

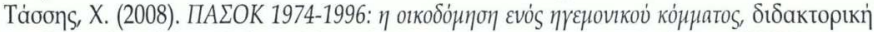

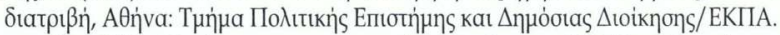

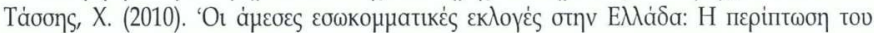

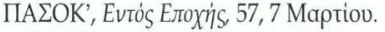

Teorell, J. (1999). 'A Deliberative Defence of Intra-Party Democracy', Party Politics, 5, 3: 363-382.

van Biezen, I. (2004). 'Political Parties as Public Utilities', Party Politics, 10, 6: 701-722 
Ward, S., R. Gibson \& P. Nixon (2003). 'Parties and the Internet: an overview' ото Gibson, R., P. Nixon \& S. Ward (eds), Political Parties and the Internet: Net gain?, London, New York: Routledge.

Weeks, L. (2007). 'Candidate selection: democratic centralism or managed democracy?' oto Gallagher, M. and M. Marsh (eds), How Ireland Voted 2007: the full story of Ireland's general election, Basingstoke: Palgrave/Macmillan.

Young, L. \& W. Cross (2002). 'The Rise of Plebiscitary Democracy in Canadian Political Parties', Party Politics, 8, 6: 673-699. 